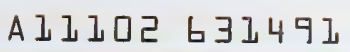

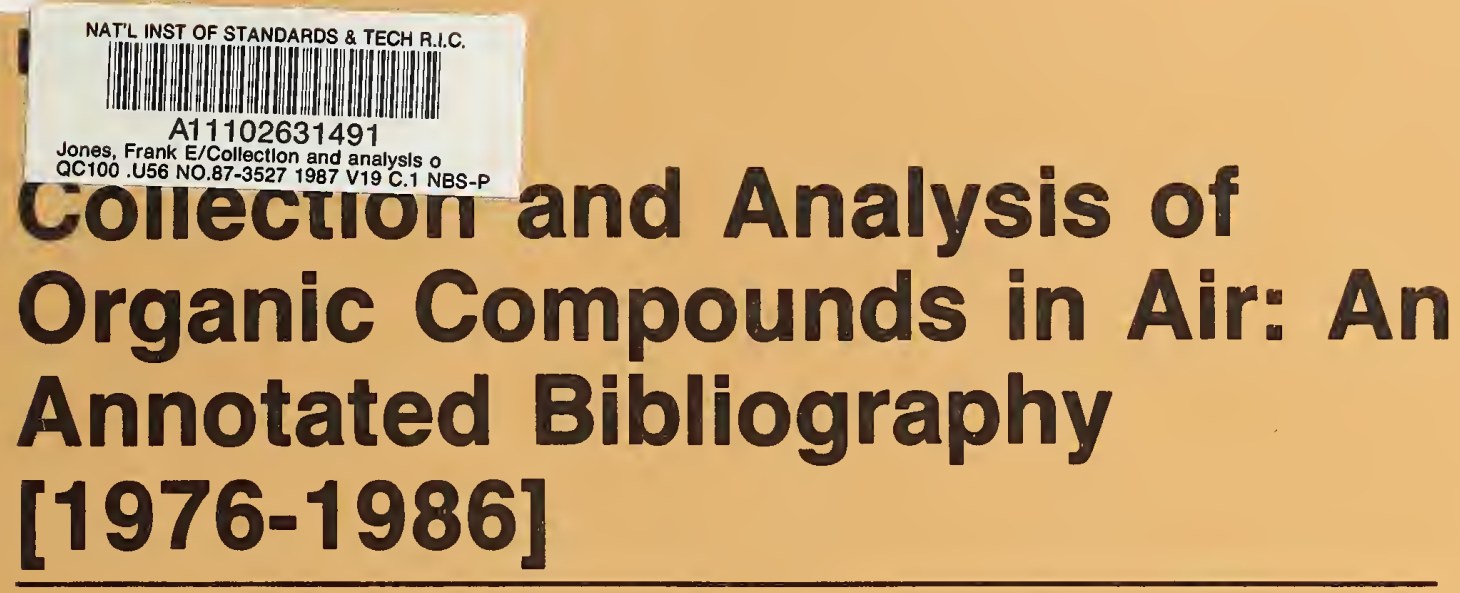

Frank E. Jones

U.S. DEPARTMENT OF COMMERCE

National Bureau of Standards

National Engineering Laboratory

Center for Chemical Engineering

Chemical Process Metrology Division

Process Sensing Group

Gaithersburg, MD 20899

February 1987

Prepared for:

$Q C$

100

.456

$87-3527$

1987

c. 2 



\section{NBSIR 87-3527}

\section{Collection and Analysis of Organic Compounds in Air: An Annotated Bibliography [1976-1986]}

Frank E. Jones

U.S. DEPARTMENT OF COMMERCE

National Bureau of Standards

National Engineering Laboratory

Center for Chemical Engineering

Chemical Process Metrology Division

Process Sensing Group

Gaithersburg, MD 20899

February 1987

Prepared for:

U.S. Army

Chemical Research, Development and Engineering Center

Aberdeen Proving Ground, MD 21010-5423 


\section{COLLECTION AND ANALYSIS OF}

ORGANIC COMPOUNDS IN AIR: AN

ANNOTATED BIBLIOGRAPHY

[1976-1986]

Frank E. Jones

U.S. DEPARTMENT OF COMMERCE

National Bureau of Standards

National Engineering Laboratory

Center for Chemical Engineering

Chemical Process Metrology Division

Process Sensing Group

Gaithersburg, MD 20899

February 1987

Prepared for:

U.S. Army

Chemical Research, Development and Engineering Center

Aberdeen Proving Ground, MD 21010-5423

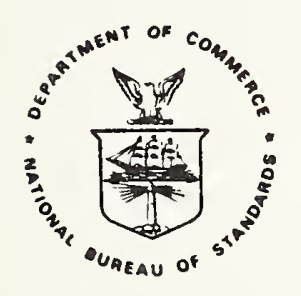

U.S. DEPARTMENT OF COMMERCE, Malcolm Baldrige, Secretary NATIONAL BUREAU OF STANDARDS, Ernest Ambler, Director 

Collection and Analysis of Organic

Compounds in Air:

An Annotated Bibliography (1976-1986)

\author{
Frank E. Jones \\ Process Sensing Group \\ Chemical Process Metrology Division \\ National Bureau of Standards \\ Gaithersburg, MD 20899
}



Abstract

Page

Introduction

iii

A. General

1

B. Standard Operating Procedures

27

Subject Index

33

Author Index

46 


\section{$\underline{\text { ABSTRACT }}$}

This is a selected and annotated bibliography of sources of methodology for the collection and analysis of volatile and semi-volatile organic compounds present in air. The most prevalent methodology is the collection and preconcentration of organic compounds in a tube or cartridge containing an adsorbent, and subsequent thermal desorption of the collected compounds on the column of a gas chromatograph (GC), GC/mass spectrometer (MS), or GC/MS/computer system for analysis. The performance of adsorbents such as porous polymer adsorbents, and the optimization and standardization of methodology are of particular interest. The bibliography comprises 68 general citations and 17 standard operating procedures.

Keywords: Adsorption; adsorbent cartridges; bibliography; analysis;

GC/MS/computer systems; porous polymer adsorbents; standardized methodology; thermal desorption; volatile and semi-volatile organic compounds 


\section{INTRODUCTION}

The collection and analysis of volatile and semi-volatile organic compounds present in air is of broad interest and of particular interest in ambient air pollution. The most prevalent methodology is the collection and preconcentration of organic compounds in a tube or cartridge containing an adsorbent (such as Tenax-GC), and subsequent thermal desorption of the collected compounds on to the column of a gas chromatograph (GC), GC/mass spectrometer (MS), or GC/MS/computer system for analysis. One of the objectives of the work of which this annotated bibliography is a part is the optimization and standardization of the methodology for the collection and analysis of the volatile and semi-volatile organic compounds of interest.

References to relevant literature were acquired through a computer search of various data bases by the Research Information Center of the National Bureau of Standards; this initial collection of references was supplemented from current literature and other sources. The period 19761986 was searched in order to concentrate on recent published advances in methodology and instrumentation.

The bibliography comprise 68 general citations and 17 standard operating procedures. It was not the intent to be exhaustive but rather to be selective in citing items of particular or related relevance to the work of interest. Likewise, the summaries for the citations include items of particular or related interest. 
In order to specify adequately procedures and techniques, identification of products and apparatus have been made. Such identification does not imply recommendation or endorsement by the National Bureau of Standards, nor does it imply that the products or apparatus identified are necessarily the best available for the purpose. Also, opinions expressed or implied in the summaries are those of the authors of the individual citations.

The author gratefully acknowledges the contributions of Diane Cunningham in making the computer search, the encouragement of Dr. Amnon Birenzvige, the support of the U.S. Army Chemical Research, Development and Engineering Command, and the typing of the manuscript by Deb Musumeci, Gina Kline, and Chris Mueller. 


\section{A. GENERAL}

[1] Ackley, M. W.

Residence Time Model for Respirator Sorbent Beds

Am. Ind. Hyg. Assoc. J. 46, 679-689 (1985)

In this article an experimental sorbent bed residence time model was developed for collecting reliable sorbent bed performance data. The model is based on the unique relationship between breakthrough time and bed residence time. The author claims that the resulting fundamental sorbent characteristics can be applied to predict the performance of any cartridge or canister with knowledge of the concentration of the contaminant, the volume of the adsorbent, and the airflow rate. The ASC I/SO, system was used to demonstrate the model and its application. The author concluded that the model "(1) provides fundamental performance characteristics for any sorbent/gas or sorbent/vapor system; (2) can be used to reliably predict the performance of respirator cartridges and canisters knowing only the contaminant concentration, flow rate and volume of adsorbent; (3) is applicable to both adsorption and chemisorption processes and can be structured to include the effects; (4) does not account for wall heat transfer effects."

[2] Alder, J. F., Hildebrand, E. A., and Sykes, J. A. W. Automatic Two-Stage Thermal Desorption Gas Chromatography for LowVolatility Organic Vapour Determination Analyst 110, 769-773 (1985)

This paper reports on an investigation of the use of a commercially available automatic thermal desorption device for determining the vapor, at trace levels, from low-volatility compounds. The desorption device was coupled through a heated stainless steel transfer pipe to a gas chromatograph fitted with a column containing $4-5 \%$ of free fatty acid phase on Chromosorb $W$ AW DMCS (60-80 mesh). The output of the flame ionization detector was fed through the gas chromatograph electronics to a recording integrator. The automatic two-phase thermal desorption gas chromatography mode of operation was found to be useful in determining the vapor from methyl salicylate over the range $1 \mathrm{ng}-1 \mathrm{\mu g}$, and 2,2'-dichlorodiethyl ether over the range 10ng-100ug. The authors stated that there was a problem due to memory effects, which could be accommodated. They suggested that some equipment modification would be required before the routine application of the method to relatively involatile compounds would be possible. The authors declared that there was no intention of any direct or implied criticism of the manufacturer of the device or of the design of the instrument.

[3] Anderson, K., Hallgren, C., Levin, J.-0., and Nilsson, C.-A. Determination of Ethylenediamine in Air Using Reagent-Coated Adsorbent Tubes and High-Performance Liquid Chromatography, on the 1-Naphthylisothiourea Derivative

Am. Ind. Hyg. Assoc. J. 46, 225-229 (1985)

A method for trace analysis of ethylenediamine in air was developed to overcome problems encountered in the analysis of amines: 1) amines are difficult to collect and analyze since they are sensitive to oxidation and degradation; 2) the low ultra-violet absorptivity of this functional group limits the applicability of high-performance liquid chromatographic (HPLC) 
methods to the analysis of amines. The reported chemisorption method uses 1-naphthylisothiocyanate coated on XAD-2 to trap ethylenediamine. The 1naphthylisothiourea derivative formed is subsequently desorbed using tetrahydrofuran and is directly injected into an HPLC. Derivatization of the amine directly upon collection stabilizes the molecule, facilitating transportation and storage prior to analysis and final chromatographic separation. The minimum detectable quantity corresponding to peak height equal to four times the noise level was approximately one nanogram for a pure standard of the derivative at 254 nanometers, and 0.3 nanogram at 229 nanometers.

[4] Bailey, A., and Hollingdale-Smith, P.A. Passive Sampling and Dosimetry In Trace-Organic Sample Handling, E. Reid, editor (John Wiley and Sons, Halsted Press, Chichester, England, 1981) pp. 43-50

Work carried out at the Chemical Defense Establishment (C.D.E.), Porton Down, Salisbury, U.K., on the development of a passive sampling device for personal atmospheric monitoring is described. The basis of the sampling method is the transfer of gas or vapor from the air being sampled to a sink; the rate is defined by a diffusional resistance. The C.D.E. diffusion sampler uses a porous polypropylene film as the transfer membrane and charcoal cloth as the adsorptive sink. Variations in sampling rate with changes in temperature, humidity, and air velocity; storage stability; and sample recovery are discussed. Results obtained from passive samplers and dynamic samplers were comparable.

[5) Bisgaard, P., Molhave, L., Reitz, B., and Wilhardt, P. A Method for Personal Sampling and Analysis of Nanogram Amounts of Formaldehyde in Air

Am. Ind. Hyg. Assoc. J. 45, 425-429 (1984)

This article describes a method, and tests thereof, for monitoring exposure to formaldehyde at nanogram levels. The method forms the basis of a commercial sampling tube; it involves collection on Chromosorb $\mathrm{W}$ coated with $0.6 \%$ 7-amino-5-hydroxy-2-naphthalenesulfonic acid in concentrated sulfuric acid, desorption with concentrated sulfuric acid, and colorimetric or fluorimetric determination of the reaction product. The standard sampling tube consists of three sections: 1) the first section containing a drying agent which removes water vapor from the air sample; 2) a second section containing the solid sorbent material which forms a fluorescent compound during exposure to formaldehyde; and 3) a back-up section containing the same sorbent material. The sampling 3 tubes were exposed to formaldehyde concentrations in the range $0.2-0.8 \mathrm{mg} / \mathrm{m}^{3}$. Most tests for the evaluation of the sampling and analytical principle were performed in dry air and without drying sections, leaving the problem of finding a suitable desiccant to be solved later. Studies of capacity, interference, and stability of the formaldehyde samples were made. The authors conclude that both fluorimetric and colorimetric determinations in acid solution were adequate for measurements of small amounts of formaldehyde in air; however, if measurements of more than 15 minutes duration are taken the adequacy of a desiccant still remains to be verified.

[6] Bishop, E. C., and Hossain, M. A.

Field Comparison Between Two Nitrous Oxide $\left(\mathrm{N}_{2} \mathrm{O}\right)$

Passive Monitors and Conventional Sampling Methods 
Am. Ind. Hyg. Assoc. J. 45, 812-816 (1984)

The purpose of the investigation reported in this article was to evaluate two commercial passive diffusion monitors (referred to here as $\mathrm{R}$ and $\mathrm{S}$ ) for use in determining waste nitrous oxide $\left(\mathrm{N}_{2} \mathrm{O}\right)$ concentrations in U.S. Air Force medical, dental, and veterinary facilities. A unique chamber for field evaluations was designed, built, and used. The chamber exposed all test devices to the same environment and provided for real-time monitoring of exposure agents; a large port on the side of the chamber was connected to an infrared analyzer to continuously monitor the $\mathrm{N}_{2} \mathrm{O}$ concentration. The $\mathrm{R}$ monitor utilizes the principle of molecular diffusion with a molecular sieve as the collection medium. Two sections of adsorbent were packed in an aluminum tube covered with plastic tubing. The S monitor contained a desiccant section preceding the molecular sieve sorbent section. Both monitors were thermally desorbed and the samples were analyzed by IR by the respective manufacturers. Bag samples collected by withdrawing air from the chamber were analyzed by the USAF. The results, covering the range 4 to 330 $\mathrm{ppm} \mathrm{N}_{2} \mathrm{O}$, indicated an "overall accuracy" of $+30.5 \%$, $+40 \%$, and $\pm 180 \%$ for the $\mathrm{R}$ monitor, the bag sampler, and the $\mathrm{S}$ sensor, respectively.

[7] Bishop, R. W., Ayers, T. A., and Rinehart, D. S. The Use of a Solid Adsorbent as a Collection Medium for TNT and RDX Vapors

Am. Ind. Hyg. Assoc. J. 42, 586-589 (1981)

The study reported in this article was conducted to determine the feasibility of using a tube containing a solid adsorbent for the efficient collection of TNT vapors and RDX vapors. Sampled air was pumped through sorbent tubes containing Tenax-GC resin 20/35 mesh; this sorbent was selected based on its sorption capability, inertness, and hydrophobicity . 63 lorisil was also investigated as a sorbent. Gas chromatography with a ${ }^{2} \mathrm{Ni}$ electron capture detector utilizing a glass column packed with $6 \%$ oV-101 on $80 / 100$ mesh Gas Chrom was used for analysis. To determine desorption efficiencies, the front sections of several sets of sorbent tubes were spiked directly with stock TNT/RDX acetone solutions. Acetonitrile was used for desorption. The work demonstrated that Tenax is an effective sampling medium for collecting vapor concentrations of TNT and RDX. The vapor generation method, involving the use of a heated generation chamber (at $200^{\circ} \mathrm{C}$ ) to produce vapor concentrations of the explosives, proved to be a simple but effective technique. The authors concluded that Florisil did not show suitable potential as a means for collecting TNT vapors or RDX vapors.

[8] Borders, R. A., Gluck, S. J., Sowle,, W. F., and Melcher, R. G. Development and Validation of Personal Monitoring Methods for Low Levels of Acrylonitrile in Workplace Atmosphere: II. Thermal Desorption and Field Validation

Am. Ind. Hyg. Assoc, J. 47, 158-163 (1986)

Field validation studies for determination of acrylonitrile (AN) in air were conducted at three sites with the use of the methods developed in a companion article (outlined in [9]) and an intermediate thermal desorption technique. This technique used a commercially available thermal desorber which desorbed collected organics into a heated storage chamber; aliquots were then injected through a gas sampling valve into a gas chromatograph. The thermal desorption sample tubes used in these studies were designed 
especially for the collection of acrylonitrile in the presence of less volatile compounds. The dual-bed tube (Tenax-GC with Carbosieve B) was designed from breakthrough volume data for AN on various solid sorbents; the purpose of the Tenax was to act as a filter for the Carbosieve B. AN was retained only slightly by Tenax and was trapped by the Carbosieve $B$. The field validation studies showed that the methods developed in the laboratory were effective in the field under a variety of conditions at concentrations of acrylonitrile ranging from 0.05 to $5 \mathrm{ppm}$. The dual-bed collection tube exhibited high collection efficiency and no breakthrough was observed under any of the test conditions. High humidity and the presence of other organic compounds did not affect the collection or recovery of AN. There was no loss in recovery for samples stored for periods of up to 56 days at room temperature. The total injection thermal desorption technique, the most sensitive of the methods in this study, gave excellent recovery and precision.

[9] Borders, R. A., Melcher, R. G., and Gluck, S. J. Improved Methodology for Field Validation of Industrial Hygiene Monitoring Methods

Am. Ind. Hyg. Assoc. J. 45, 299-305 (1984)

This article describes a statistical method to evaluate a field validation (of industrial hygiene monitoring methods) experiment, methodology to perform the experiment, and equipment which facilitates the experiment. For field validation, it is necessary to prepare accurately spiked sampling tubes which can be sampled side-by-side with a normal sample, to determine the recovery and whether the recovery has been affected. Field spiking is also a test of the integrity of the sampling, transportation, and analytical procedures. The Dynamic Atmosphere Generation System (DAGS) simultaneously produced multiple sampling tubes spiked at known concentrations without the use of a solvent (other than clean air). Two sampling manifolds are described which allow multiple field samples to be taken using one pump. The use of the DAGS for spiking samples was found to be quite convenient and rapid for gases and relatively volatile liquids. Both of the field spiking manifolds were used extensively in an industrial hygiene survey for acrylonitrile and no problems were encountered with either manifold.

[10] Brown, R. H., Harvey, R. P., Purnell, C. J., and Saunders, K. J. A Diffusive Sampler Evaluation Protocol

Am. Ind. Hyg. Assoc. J. 45, 67-75 (1984)

The authors develop a diffusive sampler protocol the main features of which are: 1) emphasis on determination of the accuracy of the standard atmosphere used to calibrate the samplers; 2) emphasis on field testing the samplers in a variety of occupational environments; 3) omission of acceptance criteria based solely on accuracy. A diffusive sampler is defined as "a device which is capable of taking samples of gas or vapor pollutants from the atmosphere at a rate controlled by a physical process such as diffusion through a static air layer or permeation through a membrane, but which does not involve the active movement of the air through the sampler." The article makes recommendations for laboratory and field tests, for estimating sampler precision under different conditions, and for determining its calibration factor or curve (the standard uptake rate). The various topics treated are: uptake rate units; factors affecting uptake rate; laboratory experiments, test apparatus; independent sampling method; determina- tion of 
the effect of external air movement on sampler performance; determination of the effect of exposure concentration and time on sampler performance; exposure to zero concentration; effect of storage; determination of the effects of temperature, pressure, and humidity on sampler performance; determination of the effect of potential interferents on sampler performance; determination of standard uptake rate; field experiments including paired comparisons - personal sampling, and multiple comparisons static sampling. Two practical examples are considered in appendices.

[11] Brown, R. H., Charlton, J., and Saunders, K. J.

The Development of an Improved Diffusive Sampler

Am. Ind. Hyg. Assoc. J. 42, 865-869 (1981)

This article describes a diffusive tube-form sampler, specifically designed for thermal desorption without removing the adsorbent. The standard version of the tube-form sampler consisted of a 6-mm OD, 5-mm ID stainless steel tube $90 \mathrm{~mm}$ in length, containing $400 \mathrm{mg}$ of Porapak Q. The air gap of $15 \mathrm{~mm}$ length and $5 \mathrm{~mm}$ ID ensured that external flow effects were minimized and that the uptake was sufficient for convenient analysis, an extended length of adsorbent providing capacity. Other porous polymer adsorbents such as Tenax-GC were used successfully in trials not reported in this article. The samplers were calibrated by exposure to benzene, removal from the exposure chamber usually after 8 hours, and two-stage thermal desorption onto a gas chromatograph column. The total amount desorbed was determined gravimetrically. Laboratory trials were supplemented by field trials in parallel with a conventional pumped adsorption tube sampling system. The diffusive samplers eliminated the need for a pump and they could be used for both static and personal monitoring. Relative humidity did not affect the uptake, temperature had a small but insignificant effect for the range of temperatures at which monitoring is likely to be carried out. The authors have successfully used diffusive samplers with other analytes including styrene and acrylonitrile in addition to benzene.

[12] Brown, R. H., and Walkin, K. T. Performance of a Tube-Type Diffusive Sampler for Organic Vapours in Air

Anal. Proc. Fifth International SAC Conference, May, 1981, pp. 205208.

This article describes the contribution of the Health and Safety Executive, Occupational Medicine and Hygiene Laboratories, London, Great Britain, to the development of the tube-type diffusive sampler described in [11]. The sampler has a low sampling rate of about 1 nanogram ( $\mathrm{ng}) / \mathrm{ppm} / \mathrm{min}$, equivalent to an air volume of about $1 \mathrm{~mL} / \mathrm{min}$. For benzene sampled in a Tenax tube with a $2.3-\mathrm{cm}$ air gap, the uptake rate was $1.4+0.06 \mathrm{ng} / \mathrm{ppm} / \mathrm{min}$ over the range 1.3-78.6 ppm ( 2 hour exposure); for $50 \mathrm{ppm}$ of benzene sampled on Tenax, as above, the uptake rate was $1.4 \pm 0.04 \mathrm{ng} / \mathrm{ppm} / \mathrm{min}$ over the range 13$95 \%$ relative humidity at $20^{\circ} \mathrm{C}$. The authors observed a decrease in uptake with time of exposure which they attributed for (Tenax, Porapak, and XAD-2) to a small vapor pressure at the adsorbent surface which would reduce the concentration gradient of pollutant and hence the rate of adsorption would be reduced; they did not consider the observed change to be very serious. The moderate effect observed with benzene sampled on Tenax might be reduced by substituting a stronger adsorbent such as Porapak N. The prinicpal advantages of the tube-type diffusive sampler over badge-type designs are a 
much reduced face-velocity effect and the ease of automated analysis. The principal advantages over other diffusive tube devices were increased capacity and the elimination of turbulence effects within the tube.

[13] Brown, R. H., and Purnell, C. J.

Collection and Analysis of Trace Organic Vapour Pollutants in Ambient Atmospheres; The Performance of a Tenax-GC Adsorbent Tube

J. Chromatogr. 178, 79-90 (1979)

This article presents an analysis of the adsorption characteristics of Tenax-GC. Most chromatographic methods for the measurement of the relatively low concentrations of organic contaminants in ambient air require a concentration step before the actual analysis. One of the most frequently used concentration techniques is adsorption on solid adsorbents, particularly the use of a porous polymer adsorbent, and direct thermal desorption into the gas chromatograph. The advantages of the latter technique are principally high sensitivity and the absence of a solvent peak in the analysis. The most popular adsorbent has been Tenax-GC, a polymer of 2,6-diphenyl-pphenylene oxide, the principal advantages of which are its high temperature stability and its extremely low affinity for water vapor. The absorbent tube used in the studies described in this article was constructed of stainless steel tubing (75 mm x $4.5 \mathrm{~mm}$ ID) and contained $0.13+0.01$ gram of 40-60 mesh Tenax-GC. Before use, the tubes were conditioned under nitrogen at 250 $250{ }^{\circ} \mathrm{C}$ for 16 hours. The following topics were investigated: safe sampling volumes; direct and indirect measurement of breakthrough volume; extrapolation of retention volume data; influence of flow-rate on breakthrough volumes; influence of vapor concentration on breakthrough volumes; the effects of temperature and humidity on breakthrough volumes; determination of safe sampling volumes (defined as 50\% of the measured retention volume). Safe sampling volumes for 71 organic compounds and a plot for the interpolation of estimated values for unlisted compounds are presented. Temperature markedly affected breakthrough, breakthrough was virtually independent of humidity.

[14] Brownlow, C. S., and Que Hee, S. S. Comparison of Solid Sampling Media for Aroclor 1254 Vapor Under Dry and Humid Conditions

Am. Ind. Hyg. Assoc. J. 46, 421-426 (1985)

It was the aim of the study reported in this article to compare the sampling ability for Aroclor 1254 vapor of XAD-2, Tenax-GC, and Chromosorb 102 against deactivated Florisil under similar conditions of sampling both in the presence and absence of humidity. The sampling tubes were prepared by packing $100 \mathrm{mg}$. of the sorbent into clean Pyrex tubing (50 to $70 \mathrm{~mm}$ long; 6$\mathrm{mm}$ OD; 3-mm ID). Non-silanized glass wool plugs before and following the sampling medium held the sorbents in place. Only $50 \mathrm{mg}$ of sorbent was used in the Tenax-GC tubes because of the higher pressure drop. Each tube was vortexed for 10 seconds to ensure uniform packing. Triplicate sorbent tubes were spiked with either $0.1 \mu \mathrm{L}(2.4 \mu \mathrm{g})$ or $4 \mu \mathrm{L}(9.6 \mu \mathrm{g})$ Aroclor 1254 in hexane, corresponding to atmospheric concentrations of $10 \mu \mathrm{g} / \mathrm{m}$ and $40 \mu \mathrm{g} / \mathrm{m}^{3}$ of Aroclor 1254 when sampled at $500 \mathrm{~mL} / \mathrm{m}^{3}$ for eight hours. Another set of sampling tubes was saturated with water before spiking to assess the effect of humidity. Efficiency of recovery with hexane was determined by comparing solutions from spiked tubes with spiked 5-mL hexane solutions and also with calibration. Methanol also was evaluated as a desorption solvent. The 
authors concluded that Tenax-GC tended to be the poorest sorbent of the four, Chromosorb 102 gave precise results most consistently and so it was chosen as the sampling medium to be compared with deactivated Florisil in vapor generation studies. Chromosorb 102 (60/80 mesh) was found to be as good a sampling sorbent for Aroclor 1254 vapor as deactivated Florisil (30/60mesh), but recoveries were less precise at $90 \%$ relative humidity.

[15] Bunch, J. E., and Pellizzari, E. D.

Evaluation of Chromotographic Sorbents Used in Air Pollution Studies J. Chromatogr. 186, 811-829 (1979)

Laboratory and field experiments, performed to permit detection of potential in situ formation of chemical substances or their decomposition on the surface of Tenax-GC, XAD-2, and carbon sorbents, are described in this article. Tenax-GC was purified by Soxhlet extraction with methanol and n-pentane, respectively, for 18 hours; after drying under nitrogen atmosphere, the sorbent was heated to $150{ }^{\circ} \mathrm{C}$ for 2 hours in a vacuum oven, sized into a 35-60 mesh range, and packed into glass tubes. The sample cartridges were preconditioned by heating to $275{ }^{\circ} \mathrm{C}$ for 20 minutes under a helium purge of $20-30$ $\mathrm{mL} / \mathrm{min}$; after cooling in precleaned culture tubes, the containers were sealed to prevent contamination of the cartridges. XAD-2 sorbent cartridges were prepared in the same manner as was Tenax-GC except that thermal preconditioning was accomplished at $200{ }^{\circ} \mathrm{C}$ for 2 hours. Replicate samples and blanks were analyzed by GC equipped with flame ionization detection. Vapors were transferred from the cartridge sampler to the analytical system by thermal desorption. A GLC with electron-capture detection and a $0.2 \%$

Carbowax 1500 on Carbopack C column was also used. A GLC-MS-computer system was used for analyzing Tenax-GC cartridges when structural confirmation was required. Halogenated hydrocarbons, in trace quantities, were produced in reactions between bromine, chlorine, 2-butene, and cyclohexene, but not with ethylene or propylene. These in situ reactions were prevented by using a glass fiber filter impregnated with sodium thiosulfate in front of the sorbent cartridge to quench the reactive gases.

[16] Cox, P. C., and Brown, R. H.

A Personal Sampling Method for the Determination of Nitrous Oxide Exposure

Am. Ind. Hyg. Assoc. J. 45, 345-350 (1984)

The suitability of a diffusive sampler, described in [11], for the determination of time weighted personal and static exposures to nitrous oxide was investigated. The sampler consisted of a 6-mm OD, 5-mm ID stainless steel tube $90 \mathrm{~mm}$ in length, containing $950 \mathrm{mg}$ of molecular sieve 5A. This molecular sieve was chosen as the adsorbent based on published work on nitrous oxide; the uniform cavities selectively adsorb molecules of diameter less than 5 angstroms and retain them until displaced by heat, for example. Calibration of the sampler for various concentrations of nitrous oxide and various periods of exposure was necessitated by the dose-dependent nature of the sampler. The effects of humidity changes on diffusive uptake were found to be negligible. The mean precision (coefficient of variation) for samples taken diffusively was $9 \%$, that of spiked samples was $3.7 \%$; this precision was similar to that for conventional pump and test tube methods. The diffusive method was preferred because of its simplicity and convenience of use. 
[17] Coyne, L. B., Cook, R. E., Nann, J. R., Bouyoucos, S., McDonald, O. F., and Baldwin, C. L.

Formaldehyde: A Comparative Evaluation of Four Monitoring Methods Am. Ind. Hyg. Assoc. J. 46, 609-619 (1985)

Laboratory and field tests of the performances of four different formaldehyde monitoring devices are described in this article. The devices evaluated were a formaldehyde badge, an impregnated charcoal tube, an impinger/ polarographic system and a formaldemeter. The badge incorporated a patented multicavity diffuser element and a specific absorbing sodium bisulfite solution in a self-contained package. The impregnated charcoal tube contained $150 \mathrm{mg}$ of charcoal impregnated with a proprietary oxidizing agent, $100 \mathrm{mg}$ in the front section and $50 \mathrm{mg}$ in the back section. Two standard glass midget impingers each contained $15 \mathrm{~mL}$ of extra purified distilled deionized water; the samples collected in the impingers were analyzed by polarographic reduction of the hydrazine derivative. The formaldemeter used an electrochemical fuel cell containing two platinum electrodes to detect and measure formaldehyde concentrations. The monitoring devices were exposed to known formaldehyde concentrations. The badge had a sensitivity of 2.8 ppm-hour and accurately and simply determined time-weighted average (TWA) exposures; however, the authors reported that it was not sufficiently sensitive to measure short-term exposure limit (STEL) exposures, whereas, positive interferences resulted if 1.3-butadiene were present. The impregnated charcoal tube had a sensitivity of $0.06 \mathrm{ppm}$ (based on a 25-liter air sample volume) and measured both TWA and STEL. The impinger/polarographic method had a sensitivity of $0.06 \mathrm{ppm}$ (based on a 20-liter air sample) and accurately determined the STEL; however, it was found to be not very practical for TWA personal monitoring measurements. The formaldemeter had a sensitivity of $0.2 \mathrm{ppm}$; however, it responded to many interferences.

[18] Demian, B., Lam, K., Schindler, A., and Pellizzari, E. D. Synthesis and Characterization of Porous Polyimides for Air Sampling of Volatile Organic Compounds

In Identification and Analysis of Organic Pollutants in Air, L. H. Keith, ed. (Butterworth Publishers, Boston, MA, 1984. pp. 95-124

A range of aromatic polyimide resins were synthesized and evaluated as sorbents for vapor phase organic analysis, as an alternative to commercially available materials. A total of 55 different polyimide resins were prepared by reacting pyromellitic dianhydride or benzophenonetetracaboxylic acid anhydride with selected aromatic diamines. Laboratory tests performed to evaluate the acceptability of each resin as sorbent for trace level organic analysis included thermogravimetric analysis, gas chromatographic analysis of sorbent background, and retention volume measurements by temperature programmed gas chromatography. Sorption properties of the four most promising polyimides (designated $\mathrm{AC}-7, \mathrm{AC}-13, \mathrm{AS}-2$, and $\mathrm{ACl}-3$ ), and Tenax-GC as a reference sorbent, were further investigated by isothermal gas chromatographic measurements at zero surface coverage. Results for the selected polyimide sorbents in tests related to the trace analysis of organics in air were found to be comparable to or better than the corresponding values for Tenax-GC.

[19] Dietz, E. A., Jr., and Hoffman, V. J. Methods for Sampling and Determining Chlorotrifluoroethylene (CTFE) in Air 
Am. Ind. Hyg. J. 45, 382-385 (1984)

In this article, two new methods for sampling and analysis of chlorotrifluroethylene monomer (CTFE, a colorless, odorless gas) at concentrations exceeding $1 \mathrm{ppm}\left(4.8 \mathrm{mg} / \mathrm{m}^{3}\right)$ time-weighted average (TWA) are compared. In the first method, a 10-L Tedlar film bag was inflated with approximately 9L of air using a calibrated personal pump. A 2-cc aliquot was injected into a gas chromatograph equipped with a flame ionization detector. The CTFE concentration was inferred from peak heights or areas relative to peak height or areas observed for standards that covered the range of interest. In the second method, air was drawn through a two-sectioned (200/400 mg) charcoal sample tube. The front and back sections of the charcoal tube were transferred to separate $7-\mathrm{mL}$ vials along with $5 \mathrm{~mL}$ of toluene. After a 30-minute desorption period with periodic agitation, about $1 \mathrm{~mL}$ of toluene solution was transferred to a GC autosampler vial. CTFE concentrations were inferred from GC responses. Prior to the selection of charcoal as the adsorbent, a qualitative screening was conducted for the following adsorbent materials: Porapak R (31); Porapak Q (34); Tenax-GC (38); Porapak P (42); Porapak N (48); Porapak S (60); Silicagel (60); Porapak T (64); and charcoal (99.2). The value in parentheses is the percentage reduction of CFTE in each vial head space as compared to a control vial. The charcoal sorption procedure was recommended. The charcoal tube method was applied to field testing, following the successful laboratory validation.

[20] Dillon, H. K., Fowler, W. F., Bryant, M. L., Martin, J. J., and Sarver, E. W.

Sampling Technology

Chemical Research and Development Center, Aberdeen Proving Ground, MD, Report No. CRDC-CR-84051, May, 1984.

The potential utility of the (then) currently available vapors and associated materials for the collection of organic vapors was evaluated in this report. The types of samplers with specified solid sorbents that were investigated are: Minimonitor (Span, Inc.) wi th Tenax-GC and Porapak Q; stainless steel sampling tube (Perkin-Elmer, Inc.) with Tenax-GC and Porapak Q; organic vapor gas monitoring badge (SKC, Inc.) with Anasorb AK; i.e., Amberlite XAD-2; and the Porton Down diffusive sampler (Chemical Defence Establishment of Great Britain) with Porapak Q on a "sticky" tape disc. The samplers were evaluated with chemicals including: 2-chloroethyl ethyl sulfide, diisopropyl methylphosphonate (DIMP), methyl benzilate, and bis (butoxyethyl) phosphate.

[21] Dillon, H. K., Barrett, W. J., and Eller, P. R. Solid Sorbent Sampler for White Phosphorus in Air Am. Ind. Hyg. Assoc. J. 39, 608-614 (1978)

This article describes the use of a solid sorbent sampling tube packed with Tenax-GC (35/60 mesh) to collect samples of white (yellow) phosphorous vapor, $\mathrm{P}_{4}(\mathrm{~g})$, from air. The sorbent material was divided into a 100-mg sorbing section and a 50-mg backup section. Air was drawn through the sampling tube by a personal sampling pump. Each sorbent section was then extracted separately into xylene. A 5- $\mu \mathrm{L}$ aliquot, removed from each extract or diluted extract with a syringe, was introduced into a GC column packed with 3\% OV-1 on 100/200 mesh Gas Chrom Q. The gas chromatograph was equipped with a flame photometric detector. Tenax-GC was found to be the 
more efficient collector. An error of less than $10 \%$ was determined in the measurement of phosphorus concentrations ranging from 0.05 to $0.37 \mathrm{mg} / \mathrm{m}^{3}$, with a lower limit for acceptable precision at about $0.01 \mathrm{mg} / \mathrm{m}^{3}$.

Interferences from red phosphoms, phosphine, water vapor, or other common gases were not significant. Effects of variations in temperature, humidity, pressure, sample storage and shipping conditions, and chromatographic parameters were determined. The authors concluded that the collection of trace amounts of $\mathrm{P}_{4}(\mathrm{~g})$ on a porous polymer such as Tenax-GC appeared to provide a suitable substitute for the xylene impinger method.

[22] Easley, L. D., and Suggs, H. J.

The Effect of Low Flowrates on the Collection Efficiency of Hexane on Charcoal

Am. Ind. Hyg. Assoc. J. 46, 150-153 (1985)

In the investigation reported in this article, the effect on charcoal tube collection efficiency for hexane at flowrates in the laminar, transition, and turbulent flow modes was studied. A sample mixture of $n$-hexane in nitrogen at a concentration of $689 \mathrm{ppm}$ was passed through charcoal sorbent tubes at flowrates of $290,580,1710,2860,5400$, and $6670 \mathrm{~mL} / \mathrm{min}$ until the tubes were saturated and breakthrough occurred. Two measures of collection efficiency were used: (1) breakthrough volume, breakthrough time multiplied by the volumetric flowrate; and (2) kinetic saturation capacity (We), grams of vapor adsorbed per gram of adsorbent at breakthrough. Breakthrough time was defined as the time needed for $10 \%$ of the inlet concentration to be detected in the discharge stream. The sample tubes contained a bed of 20/40 mesh activated coconut shell charcoal, at bed weights of $200,250,300$, and $400 \mathrm{mg}$. Each tube was vibrated with a chromatograph column vibrator for 30 seconds and then a fiberglass plug was inserted. The contaminant (hexane) was detected by a gas chromatograph equipped with a fame ionization detector. The authors concluded that, under the test conditions, there were significant differences in breakthrough volumes or kinetic saturation capacities related to flowrates (laminar, transition, or turbulent); and that a different contaminant or under different test conditions, such as lower concentrations, could lead to different results.

[23] Elskamp, C. J., and Schultz, G. R.

A Solid Sorbent Air Sampling Procedure for Methyl-, Dimethyl-, Ethyl-, and Diethylamine

Am. Ind. Hyg. Assoc. J. 47, 41-49 (1986).

This paper describes the development and evaluation of a solid adsorbent tube sampler, sampling procedures, and analytical procedures for methyl-, dimethyl-, ethyl-, and diethylamine. The solid adsorbent tubes contained two sections of $20 / 50$ mesh Amberlite XAD-7 resin coated with $10 \%$ by weight of the derivatizing reagent NBD chloride (7-chloro-4-nitrobenzo-2-oxa-1,3diazole). Air was pumped through the tubes at low flowrates using a personal sampling pump. The samples collected on the coated resin were prepared for analysis by transferring front and back sections to separate vials, adding approximately $25 \mathrm{mg}$ of sodium bicarbonate followed by $2.0 \mathrm{~mL}$ of a 5\% NBD chloride in tetrahydrofuran solution, shaking on a mechanical shaker for 0.5 hour, and then heating at $60^{\circ} \mathrm{C}$ in a hot water bath for 2.5 hours. The samples (and standards) were allowed to cool and then 15- $\mu \mathrm{L}$ aliquots were injected into a high performance liquid chromatograph with a fluorescence detector or a UV/visible wavelength detector for analysis. The 
method described in this paper was tested at sample loadings equivalent to air concentration ranges of 0.5 to $30 \mathrm{ppm}$ for a sample volume of $10 \mathrm{~L}$ for the four amines studied. The method was not affected by relative humidity or by the presence of a combination of these amines in the same atmosphere.

[24] Goller, J.W.

Displacement of Polar by Non-Polar Organic Vapors in Sampling Systems Am. Ind. Hyg. Assoc. J. 46, 170-173 (1985)

This paper describes a method for collecting vapor of toluene, xylene, butanol, acetone, isopropanol, ethanol, and methanol and an analytical procedure to separate and determine the quantity of each compound. The sampling train consisted of a personal sampling pump (three pump flow rates were used to collect different sample volumes) with two charcoal tubes in series. Each of the tubes consisted of a front and a rear section; the front section contained $100 \mathrm{mg}$ of coconut based charcoal, and the rear section contained $50 \mathrm{mg}$ of charcoal. The second tube collected vapors which passed through the first tube by overloading or by selective displacement. Carbon disulfide with $1 \%$ amyl alcohol was used to desorb the vapors from the charcoal. The analysis was done by gas chromatography on a 10\% FFAP with $80 / 100$ mesh Chromosorb $W$, the detector was a flame ionization detector. Each of the sections of the tubes was analyzed separately. The authors concluded that non-polar compounds will displace polar compounds in charcoal sampling systems; competitive adsorption also occurs among polar compounds. They also concluded that, when sampling air containing mixtures of organic vapors of unknown concentrations, it may be helpful to use back-up tubes in case of breakthrough; also that the back-up should contain silica gel when the mixture contains both polar (especially ethanol and methanol) and nonpolar compounds.

[25] Gonzalez, J., and Levine, S. P.

The development and Evaluation of a Thermaliy-Desorbable Miniature Passive Dosimeter for the Monitoring of Organic Vapors

Am. Ind. Hyg. Assoc. J. 47, 339-346 (1986).

This paper describes the development and evaluation of a miniature passive dosimeter for sequential monitoring of short-term exposure limits of organic vapors and/or for the monitoring of low concentration levels of organic vapors. The sampling medium was a fraction (5-mm diameter by $0.58-\mathrm{mm}$ disk) of the DuPont strip used in Pro-Tek organic vapor badges. The effects of humidity, background air pollution, repeated re-use of sorbent, and transportation and storage of collected samples were investigated. The vapor generator, dynamic exposure, and analysis system used was capable of shortperiod square concentration waves. Benzene was used as the test vapor. Analysis of exposed samples was performed by thermal desorption and gas chromatography. Factors included in laboratory evaluation of the monitor were desorption, efficiency, capacity, sensitivity, accuracy and precision concentration level, environmental conditions (e.g., air face velocity, relative humidity), and sample stability during short and long periods of time. The authors concluded that performance of the monitor was not affected by concentration level (in the range 0.1 to $50 \mathrm{ppm}$ ), relative humidity up to $80 \%$, and air face velocities of 40 to $100 \mathrm{fpm}$. The calculated overall system accuracy was $14 \%$ for the range 0.1 to $1 \mathrm{ppm}$, and $15 \%$ for the range 1 to $50 \mathrm{ppm}$. 
[26] Heitbrink, W. A., and Crouse, W. E.

Application of Industrial Hygiene Air Sampling Data to the Evaluation of Controls for Air Contaminants

Am. Ind. Hyg. Assoc. J. 45, 773-777 (1984)

In this paper, the following hypothesis is stated: "At an operation where air contaminants are well-controlled, there should be no significant difference in concentration between the worker's exposure, area samples collected near emission sources and background area samples collected away from emission sources". The hypothesis requires the use of concentration differences to establish whether a control is effective and whether important emission sources are being controlled. Stating this hypothesis as a null hypothesis, statistical tests can be used to evaluate its validity. The purpose of the paper is to discuss the application of the following statistical methods: analysis of variance, and Duncan's Multiple Range Test.

[27] Hunt, R. J., Neubauer, N. R., and Picone, R. F. An Improved Procedure for Sampling and Analysis of Dinitrotoluene Vapor Concentrations in Workplace Air Am. Ind. Hyg. Assoc. J. 41, 592-594 (1980)

A method is described which combines collection of dinitrotoluene (DNT) vapor onto silica gel sample tubes, desorption in chloroform, and gas chromatographic determination of the various isomers of dinitrotoluene. The sampling tubes were commercially available. Injections of solutions of DNT in chloroform were made into a GC glass column packed with $1.5 \%$ FFAP (Free Fatty Acid Phase) on 60/80 mesh Chromosorb G (acid washed and dimethyldichlorosilanized). Concentrations of less than $10 \%$ of the Threshold Limit Value $\left(1.5 \mathrm{mg} / \mathrm{m}^{3}\right)$ for dinitrotoluene were determined in a 50-1iter air sample.

[28] Hurley, G. F., and Ketcham, N. H.

A Solid Sorbent Personal Sampling Method for the Determination of Acrolein in Air

Am. Ind. Hyg. Assoc. J. 39, 615-619 (1978)

This paper describes a personal air sampling method, using coated activated carbon with subsequent analysis by gas chromatography, developed for the analysis of acrolein in the 0.05 to $5 \mathrm{ppm}$ range for 5-liter air samples. The adsorbent chosen was activated carbon coated with a 5\% ethanolic solution of hydroquinone, an acrolein polymerization inhibitor. Desorption of acrolein from the sorbent was accomplished by addition of carbon to cooled ethylene chloride, followed by a 30-minute contact with occasional shaking. The chromatographic column packing was 9\% Carborwax 20M-Terephthalic Acid on 40/60 mesh Chromosorb T. The detector was a flame ionization detector. The peak height, or area, of the acrolein at 4.6 minutes retention time was measured. The amount of acrolein present was determined from a calibration standard or standard curve, this value was corrected by a previously determined desorption efficiency for the amount of acrolein present. The authors concluded that a sensitivity of about $0.25 \mu \mathrm{m}$ of acrolein per half $\mathrm{mL}$ of solvent ( $0.02 \mathrm{ppm}$ of acrolein for a 5 -L air sample) was possible.

[29] Jonas, L. A., Sansone, E. B., and Farris, T. S. The Effect of Moisture on the Adsorption of Chloroform by Activated Carbon 
Am. Ind. Hyg. Assoc. J. 46, 20-23 (1985)

This paper reports a study of the effect of moisture on the ability of a granulated activated carbon to adsorb chloroform vapor from a flowing airstream under three test conditions: (1) chloroform and water vapor were introduced concurrently into a dry carbon bed; (2) dry chloroform was introduced into a humidified carbon bed; and (3) humidified chloroform was introduced into a carbon bed at the same relative humidity. The criterion for bed performance was 1\% breakthrough time, the time at wich the ratio of exit to inlet gas concentration was 0.01 . Kinetic adsorption tests were carried out on a vapor adsorption test apparatus which was modified to permit the generation and subsequent mixing of up to three vapors simultaneously. The vapors penetrating the bed were passed onto a gas chromatograph glass column packed with $28 \%$ Pennwalt $223+4 \% \mathrm{KOH}$ on $80 / 100$ mesh Gas Chrom R support. A flame ionization detector was used. For the 3 tests, chloroform concentration was essentially constant at $108+2 \mathrm{mg} / \mathrm{cm}^{3}$, relative humidity ( $\mathrm{RH}$ ) varied from 0 to $97 \%$. The results indicated that, for a dry carbon bed, the $1 \%$ breakthrough time for chloroform adsorbed from atmospheres of RH from 13\% to $95 \%$ was essentially the same as that when $\mathrm{RH}=$ $0 \%$; for humidified carbon beds, no change in $1 \%$ breakthrough time for chloroform was observed until RH was $>40 \%$.

[30] Kim, W. S., Geraci, C. L., Jr., and Kupel, R. E.

Solid Sorbent Tube Sampling and Ion Chromatographic Analysis of Formaldehyde

Am. Ind. Hyg. Assoc. J. 41, 334-339 (1980)

A new method for collection and analysis of atmospheric formaldehyde is discussed in this paper. The method is based on solid sorbent tube collection and ion chromatographic analysis. Ion chromatography consists of ionexchange chromatography, background ion suppression, and conductimetric detection. The solid sorbent tube was prepared with two sections of impregnated charcoal separated by silylated glass wool. The proprietary

impregnating material converts formaldehyde to formate. After the sampling, at either $50 \mathrm{cc} / \mathrm{min}$ or $200 \mathrm{cc} / \mathrm{min}$, each section of the charcoal was placed in separate centrifuge tubes; $10.0 \mathrm{~mL}$ of $0.1 \% \mathrm{H}_{2} \mathrm{O}_{2}$ solution was added to the adsorbent section and $5.0 \mathrm{~mL}$ was added to the backup section. Then, after 1 hour of occasional shaking, each sample was placed in an ultra-sonic bath for 20 minutes. After filtration through a mixed cellulose ester filter, a fraction of filtrate was injected into the anion system of an ion

chromatograph. The overall recovery of laboratory generated samples was $100 \%$ with $11 \%$ relative standard deviation.

[31] Krasnec, J.P., and Demaray, D. E.

Instrumentation for Source Sampling and Characterization of Indoor and Industrial Gaseous Pollutants

Presented at the Joint PNWIS/CPANS-APCA Annual Meeting, Calgary, Alberta, Canada, Nov. 13-15, 1985.

In this paper, sampling instrumentation design criteria for indoor/ industrial air pollution monitoring are presented. Grab samplers, passive samplers, personal samplers, single-use devices, in-situ measurement instruments, and microcomputer-controlled syringe and adsorbent tube samplers are compared. Recently introduced passive samplers and sequential grab samplers 
are described in detail, their use for sampling of toxic organic pollutants is highlighted.

[32] Krasnec, J. P., Demaray, D. E., Lamb, B., and Benner, R. An Automated Sequential Syringe Sampler for Atmospheric Tracer Studies

J. Atmos. Ocean. Technol. 1, 372-378 (1984)

The design and operation of an automated, sequential syringe sampler are described in this paper. The latest version included an advanced timing system and collected 12 sequential time-averaged air samples, a rack and pinion drive and a stepper motor provided the mechanical actuation of each syringe. A crystal-controlled oscillator, which could be preset to a variable 2-to-8 minute interval, provided the time-base. Per syringe sampling interval could be preset to give sampling times ranging from 2 to 120 minutes, permitting a total sampling time of up to 24 hours for the twelvestation sampler.

[33] Kring, E. V., Damrell, D. J., Basilio, A. N., Jr., McGibney, P. D., Douglas, J. J., Henry, T. T., and Ansul, G. R.

Laboratory Validation and Field Verification of a New Passive Air Monitoring Badge for Sampling Ethylene Oxide in Air

Am. Ind. Hyg. Assoc. J. 45, 697-707 (1984)

A new diffusion colorimetric air monitoring badge for sampling ethylene oxide is described in this paper. The badge was laboratory validated over the range 4-375 ppm-hours. The reagent pack was removed from the badge holder after exposure and analysis was performed on $1.0 \mathrm{~mL}$ of the absorbing solution. The overall sampling and analysis accuracy of the badge was \pm $13.5 \%$. The badge agreed very well, in 21 separate tests, with the most widely used pump/charcoal tube method for sampling ethylene oxide in industrial workplace environments.

[34] Kring, E. V., Ansul, G. R., Basilio, A. N., Jr., McGibney, P. D., Stephens, J.S., and O'Dell, H. L.

Sampling for Formaldehyde in Workplace and Ambient Air Environments-Additional Laboratory Validation and Field Verification of a Passive Air Monitoring Device Compared with Conventional Sampling Methods.

Am. Ind. Hyg. Assoc. J. 45, 318-324 (1984)

This paper presents: (1) additional laboratory validation work on a new diffusional badge (see [33]) designed for colorimetric analysis and broad sampling range; (2) field verification tests, and (3) some observations on the most widely used (then) independent method, NIOSH P\&CAM 125. Four independent sampling methods were used in all laboratory studies: the pump/impinger sampling method, NIOSH P\&CAM 125; the pump silica gel tube monitoring method; the CEA Model 555 monitor; and the Lion Formaldemeter. The field test protocol was based on NIOSH sampling strategy, a verification plan developed jointly with the Ethylene Oxide Industry Council and past experience. Laboratory validation tests confirmed an overall accuracy of \pm 9.6 to $\pm 11.5 \%$ for the badge over the exposure range of $0.12-6.8 \mathrm{ppm}$. Laboratory test data also showed that the badge met NIOSH and OSHA accuracy requirements of $<+25 \%$ down to 1.6 ppm-hours (200 ppb) for an 8-hour TWA exposure, was capabile of accurately sampling for 15-minute exposures, and 
was not affected by pressure or relative humidity variations. Results of field tests at three different plant sites showed the badge to have excellent correlation with three commonly used methods for monitoring formaldehyde.

[35] Kring, E. V., Ansul, G. D., Henry, T. J., Morello, J. A., Dixon, S. W. Vasta, J. F., and Hemingway, R. E.

Evaluation of the Standard NIOSH Type Charcoal Tube Sampling Method for Organic Vapors in Air

Am. Ind. Hyg. Assoc. J. 45, 250-259 (1984)

This paper reports on a study in which standard commercially-available NIOSH-type charcoal tubes were used as an independent check on the concentration in dynamic exposure chambers. Tests were conducted for 67 hours at $80 \%$ relative humidity to simulate the worst conditions for industrial TWA monitoring. Charcoal tube flow rates were controlled at $50 \mathrm{~cm}^{3} / \mathrm{min}$. All desorbed samples were analyzed on a gas chromatograph equipped with a flame ionization detector and automatic liquid sampler. An improved protocol was used to test a number of the more common organic airborne contaminants; 14 of the 22 compounds failed to meet NIOSH accuracy requirements, suggesting to the authors that workers in the industrial hygiene field should consider the charcoal tube method only as an independent method and not as a primary standard for air monitoring. The authors concluded that laboratory test data indicated that the NIOSH charcoal tube sampling method has serious deficiencies when used to determine the true exposure concentrations of many common industrial organic compounds in moist air, and they strongly recommended laboratory validation of charcoal tubes prior to field sampling.

[36] Kropscott, B. E., Coyne, L. B., Campbell, R. A., Kastl, P. E., and Sowle, W. F., III

Robotic Applications Within Dow's Health and Environmental Sciences Laboratory

In Advances in Laboratory Automation Robotics 1985, Strimaitis, J. R., and Hawk, G. L., eds. (Zymark Corp., Hopkinton, MA, 1985) pp. $131-147$

This paper presents two examples of automated sample preparation using a laboratory automation system (robot): (1) sample preparation and method optimization for subsequent chromatographic analysis; (2) whole tube desorption, a new technique for analyte desorption from charcoal tubes in industrial hygiene surveys. Sample extracts were analyzed using a gas chromatograph equipped with an electron capture detector and a flame ionization detector. A data system was used to integrate peak areas and determine concentrations from external standard calculations. The automated whole tube desorption method avoided removal of the charcoal sorbent from the glass sampling tube by desorbing the entire air sampling tube with chilled solvent inside a test tube. The recovery of spiked samples desorbed using the whole tube desorption method was similar to that for spiked samples desorbed using a validated industrial hygiene monitoring method, which required the removal of the sorbent prior to desorption. The authors concluded that the laboratory automation system provided the accuracy, precision, and reliability to automate and optimize the feed extractions; that whole tube desorption had been developed as a viable means of desorbing analytes from charcoal tubes; and that laboratory robots should not be thought of as a replacement of the analyst. 
[37] Krost, K. J., Pellizzari, E. D., Walburn, S. G., and Hubbard, S. A. Collection and Analysis of Hazardous Organic Emissions

Anal. Chem. 54, 810-817 (1982)

The primary goal of the research program described in this paper was to develop methodology for the reliable and accurate collection and analysis of hazardous vapors present simultaneously in the atmosphere down to nanogram per cubic meter amounts. This paper summarizes the overall progress made on the development of an analysis system encompassing the collection and concentration of organic pollutants from ambient air using tubes packed with polymeric beads. After sampling, the cartridges were thermally heated under a helium flow, the compounds desorbed, cryofocused, and subsequently introduced into a high-resolution glass or fused capillary for characterization and measurement by gas chromatography/mass spectrometry/computer techniques. Cartridges used to concentrate organic vapors consisted of a $1.5 \mathrm{~cm} \times 6.0 \mathrm{~cm}$ bed of Tenax-GC (35/60); two or three cartridges were designated as blanks for assessing occurrence of contamination. Thermal desorption of sampling cartridges was accomplished by passing helium through the cartridge in a preheated (ca. $270{ }^{\circ} \mathrm{C}$ ) chamber for 8 minutes at a flowrate of about 15 $\mathrm{mL} / \mathrm{min}$, into a liquid-nitrogen-cooled nickel capillary trap.

\section{[38] Langhorst, M. L.}

Monitoring Airborne Reactive Chemicals by Derivatization and High

Performance Thin Layer Chromatography-Anhydrides, Acid Halides, Isocyanates

Am. Ind. Hyg. Assoc. J. 46, 236-243 (1985)

This paper discusses work on a versatile reagent-coated solid sorbent tube developed for monitoring airborne reactive chemicals including acetic anhydride (AcAn), chloroacetyl chloride (CAC), and isocyanatoethyl methacrylate (IEM). Since all three of these chemicals react readily with reactive hydrogens, e.g., water vapor, amines, and primary alcohols, long-term collection without derivatization is precluded. The air sampling sorbent was 120/140 mesh GLC-110; the derivatizing agent was 0.20\% 1-(2-pyridyl) piperazine. After collection of the sample, the sorbent from each tube was desorbed in two $\mathrm{mL}$ of hexane (five $\mathrm{mL}$ for acetic anhydride tubes), shaken for five minutes on a mechanical shaker, and analyzed by high performance thin layer chromatography. The concentration of AcAn, CAC, or IEM in the original air was calculated against external standards. The recoveries for AcAn, CAC, and IEM were $97.5 \%, 95.2 \%$, and $85.0 \%$, respectively. Humidity effects, storage effects, and potential interferences were also evaluated.

[39] Levine, S. P., Gonzalez, J. A., and Kring, E. V. A Dynamic Vapor Exposure System for Evaluating Passive Dosimeters Am. Ind. Hyg. Assoc. J. 47, 347-353 (1986)

The design and validation of a dynamic vapor exposure system for the evaluation of passive dosimeters (see [46]) for ceiling exposure monitoring of low concentration levels are reported in this paper. The test vapor generator consisted of a thermally regulated diffusion tube assembly, a dilution air cleaning device, flow regulating and humidifying assembly, a mixing chamber, rotameters for flow rate monitoring, and associated tubing. The generator vapor (benzene) passed through a mixing chamber into the exposure chamber. The exposure chamber concentration was determined by two independent in-situ instruments: (1) a real-time total hydrocarbon monitor (photoionization 
detector) calibrated against a test mixture traceable to National Bureau of Standards primary standards; and (2) a near-real-time monitor (gas

chromatograph, GC, with a flame ionization detector) calibrated against liquid standards and vapor primary standards. The concentration profiles were found to be highly reproducible and accurate to the 0.1-ppm level (sample loadings of $10 \mathrm{ng}$ benzene per sample). The authors concluded that the system yielded results with a high accuracy and precision over a wide range of benzene concentration ( 0.1 to $50 \mathrm{ppm}$ ) and exposure time ( 5 to $30 \mathrm{~min}$ ).

Significant features of the system included a combined inlet system for the thermal desorption of passive dosimeters and the direct injection of vapors and liquids, and the use of iso-octane as a solvent for benzene for liquid calibration of the GC at very low levels.

[40] Mason, D. W., Dillon, H. K., and Glaser, R. A. Sampling and Analytical Methods for the Determination of Monochloroacetic Acid in Air Am. Ind. Hyg. Assoc. 47, 14-21 (1986)

The development and validation of a sampling and analytical method for the determination of monochloroacetic acid (MCA) vapor in workplace air are described in this paper. Collection on silica geI and collection on a reactive, impregnated filter (sodium bicarbonate on quartz fiber) were considered. MCA was desorbed from both types of collection media with reagent grade distilled deionized water; ion chromatography was used to determine the monochloroacetic anion. The sorbent tubes contained silica gel (20/40 mesh), divided into a 100-mg sorbing section and a 50-mg back-up section. The impregnated filters consisted of quartz filter disks with a 5um pore size, which had been soaked in a saturated solution of sodium bicarbonate and then dried under vacuum. A continuous monitor was employed as an independent or reference sampling and analytical method. It was found necessary to add the silica gel solid sorbent to an aqueous solution of MCA because ions extracted from the sorbent affected the base line of the ion chromatographic response near the monochloroacetate peak. A more complex procedure was required for the reactive filters, to remove excess bicarbonate ion from the solution prior to analysis. The silica gel was deemed, from test results, to be more acceptable than the reactive filter for sampling MCA in air. Collection of $\mathrm{MCA}$ on the reactive filter showed considerable promise, however, the method was not validated because refrigeration of exposed filters or extraction of filters soon after exposure was necessary to preserve the MCA for subsequent determination. The siliģa gel method was validated in the concentration range of 0.35 to 29 $\mathrm{mg} / \mathrm{m}^{3}$ in 3-L air samples, the capacity of the silica gel was in the range of 3 to $4 \mathrm{mg}$ of MCA per $100 \mathrm{mg}$ of sorbent. There were no significant interferences from glycolic acid, acetic acid, dichloroacetic acid, trichloroacetic acid, fluoride and chloride compounds, or water vapor; effects on analytical data due to variations in temperature and humidity of the test atmosphere, sample storage time, and chromatographic parameters were found to be minimal.

[41] Melcher, R. G., Borders, R. A., and Coyne, L. B. Development and Validation of Personal Monitoring Methods for Low Levels of Acrylonitrile in Workplace Atmosphere: I. Test Atmosphere Generation and Solvent Desorption Methods Am. Ind. Hyg. Assoc. J. 47, 152-157 (1986) 
The purpose of the study reported in this paper was to optimize monitoring methods and to investigate new technology for the determination of low levels of acrylonitrile $(0.05$ to $5 \mathrm{ppm})$ in workplace atmospheres. A dynamic atmosphere generation method was developed in the first phase of the study; in the second phase, various potential sorbents were investigated and compared in a laboratory validation study. Carbosieve B, Ambersorb XE-340, Ambersorb XE-347, Ambersorb XE-348, and three volumes of Pittsburgh CoconutBase (PittCB) activated charcoal were the candidate sorbents. The sorbents were desorbed by pouring into $10 \mathrm{~mL}$ of dry-ice-chilled carbon disulfide or $2 \%$ acetone in carbon disulfide and shaking for 30 minutes. The extracts were analyzed by gas chromatography with flame ionization detection (FID) or a nitrogen selective detector (PND); the limit of detection for acrylonitrile was $4 \mu \mathrm{g} / 10 \mathrm{~mL}$ and $0.2 \mu \mathrm{g} / 10 \mathrm{~mL}$ for PND, based on a 3 to 1 signal-to-noise ratio. A collection tube containing $600 \mathrm{mg}$ of PittCB charcoal was optimum for sampling for a full 8-hour shift. Ambersorb XE-348 was found to be a better sorbent for acrylonitrile and less affected by humidity. The best adsorption solvent was found to be carbon disulfide plus $2 \%$ acetone; recoveries near $90 \%$ were obtained for both the tubes containing charcoal and Ambersorb. The PND was found to be more sensitive and more selective than the FID.

[42] Moore, G., Steinle, S., and Lefebre, H. Theory and Practice in the Development of a Multisorbent Passive Dosimeter System

Am. Ind. Hyg. Assoc. J. 45, 145-153 (1984)

A new family of passive dosimeters was fabricated to allow the use of multiple sorbents and analytical techniques suited to a wide range of sampling situations. Sorbent capsules were designed both for conventional solvent desorption and to be used with a newly developed rapid thermal desorber capable of automation for multiple samples. This paper describes the development of the system together with laboratory tests and results and the effects of environmental parameters. The paper deals principally with work on solid sorbent systems.

[43] Morris, C., Berkley, R., and Bumgarner, J. Preparation of Multicomponent Volatile Organic Standards Using Static Dilution Bottles Analytical Letters 16 (A20), 1585-1593 (1983)

This paper discusses a static dilution bottle designed to prepare multicomponent volatile organic standards, in helium. Different concentrations may be obtained by using different sized bottles, by adjusting the component amounts introduced into the bottles, or by varying the amount of vapor removed by gas-tight syringes for injection into an analytical instrument such as a gas chromatograph/mass spectrometer or into a solid adsorbent sample collection cartridge. Mixtures of up to 35 compounds, each having a vapor pressure greater than 1 Torr at $20{ }^{\circ} \mathrm{C}$, were prepared and applied for one week with no loss of precision. The procedure offers flexibility in producing calibration curves and preparing quality assurance standards.

[44] Pankow, J. F., and Kristensen, T. J. Effects of Flow-Rate and Temperature on Thermal Desorbability of Polycyclic Aromatic Hydrocarbons and Pesticides from Tenax-GC Anal. Chem. 55, 2187-2192 (1983) 
The purpose of the research described in this paper was to investigate the desorbability of a set of compounds which were generally not considered to be easily thermally desorbable from Tenax-GC. A main objective was to investigate the extent to which increasing the carrier flow rate could be used to accomplish a quantitative transfer to a fused silica capillary column at minimal desorption temperatures while maintaining high resolution in the subsequent chromatographic run. Polynuclear aromatic hydrocarbons larger than benz[a]-anthracene were studied. The desorbabilities of the compounds were investigated as a function of helium carrier gas flow rate and desorption temperatures; other carrier gases of larger molecular sizes were also investigated. The desorption apparatus consisted of a cartridge packed with $0.110 \mathrm{~g}$ of $35 / 60$ mesh Tenax-GC, with an injection septum mounted on the top end and with the bottom end interfaced to a capillary column. Each experiment consisted of loading $4.0 \mu \mathrm{L}$ of the standard on the top of the cartridge followed by a series of eight 20-min desorptions and eight accompanying runs. At the same volume flow rate, carbon dioxide, methane, ethene, and propane were not found to give more facile desorption than helium for the study compounds. The desorbing compounds were trapped on a fused silica capillary column at $-30^{\circ} \mathrm{C}$. Excellent resolution and separation number performance was maintained despite the use of high desorption carrier gas flow rates.

[45] Pellizzari, E. D., and Krost, K. J. Chemical Transformations during Ambient Air Sampling for Organic Vapors

Anal. Chem. 56, 1813-1819 (1984)

The subject of this paper is a study of potential halogenation, nitrosation, and ozonization reactions and their inhibition with sodium thiosulfate during the collection of vapor-phase organics from ambient air. The research centered on a sorbent collection method using Tenax-GC. A thermal desorption capillary gas chromatography/mass spectrometry (GC/MS) method was used to analyze analytes collected on a Tenax-GC sampling cartridge. Field in situ reaction studies were conducted by sampling ambient air using Tenax$\overline{\mathrm{GC}}$ cartridges and Tenax-GC cartridges spiked with deuterated compounds; subsequently the cartridges were analyzed to identify deuterated compounds. The use of styrene- $\mathrm{d}_{8}$ and cyclohexene- $\mathrm{d}_{10}$ spiked sampling devices and GC/MS analysis allowed the detection and identification of several deuterated oxidation and halogenated products. Oxidation was prevented when filters employed for removing particulates were impregnated with 5-10 mg of sodium thiosulfate and placed in front of the sorbent cartridge; halogenation reactions were also considerably reduced.

[46] Pellizzari, E. D., Demian, B., and Krost, K. J.

Sampling of Organic Compounds in the Presence of Reactive Organic Gases with Tenax-GC

Anal. Chem. 56, 793-798 (1984)

The testing of the Tenax-GC sampling cartridge to gain insight into potential reaction problems which may be encountered during field sampling is reported in this paper. The sampling of vapor-phase organics in the presence of reactive inorganic gases with the Tenax-GC sampling cartridge was statistically evaluated. Laboratory air containing oxidants for sampling was synthesized. A thermal desorption capillary gas chronato- 
graphy/mass spectrometry method was used for qualitative analysis of TenaxGC or analyte degradation products. Experimental results clearly demonstrated that the presence of oxidants in ambient air could produce decomposition products both from the Tenax-GC sorbent and from analytes adsorbed to the adsorbent. Removal of oxidants prior to the capture of organic vapors was investigated by use of mild reducing agents impregnated in filters for particulate. Sodium-thiosulfate-impregnated glass fiber and Teflon filters quantitatively decomposed ozone.

[47] Pellizzari, E. D., Bunch, J. E., Berkley, R. E., and McRae, J. Collection and Analysis of Trace Organic Vapor Pollutants in Ambient Atmospheres. The Performance of a Tenax GC Cartridge Sampler for Hazardous Vapors. Analytical Letters 9 (1), 45-63 (1976)

This paper reports on the evaluation of several sorbents as collection media for the quantitative concentration and analysis of volatile, hazardous, vapor-phase compounds from ambient atmospheres under a variety of conditions relevant to field sampling. The sorbents evaluated were graphitized carbon, PBL carbon, PCB carbon, SAL9190, M180B, Tenax-GC (35/60 mesh), Porapak Q (100/120 mesh), Chromosorb 101 (60/80 mesh), Chromosorb-102 (60/80 mesh), Chromosorb 104E (60/80 mesh). Tenax-GC was selected as the best available sorbent for general use because of its wide range of applicability, its thermal stability, and its low retentive index for water.

[48] Pellizzari, E. D., Gutknecht, W. F., Cooper, S., and Hardison, D. Evaluation of Sampling Methods for Gaseous Atmospheric Samples U.S. Environmental Protection Agency, Final Report on Contract No. 68-02-2991

This report describes a research program conducted to test and evaluate several alternatives for collecting and transferring samples to the laboratory for the analysis of a variety of toxic organic pollutants by gas chromatography. Sample storage media included three types of polymeric bags, glass bulbs, electropolished and Summa polished canisters, Tenax-GC and charcoal cartridges, and nickel cryogenic traps. The storage media were tested using 27 compounds including hydrocarbons, aromatics, halogenated hydrocarbons, halogenated aromatics, and oxygen-, nitrogen-, and sulfurcontaining compounds. Quantitative laboratory stability tests were conducted for $15 \%$ of the compounds over a 7-day storage period. The potential effect of inorganic gases as interferences during the collection of test compounds was quantitatively studies. An automatic two-channel ambient air sampler using sorbent cartridges as the collection media was designed and fabricated. A quality control and quality assurance program was established and maintained for all measured and analyzed data.

[49] Persoff, P., and Hodgson, A. T.

Correction for External Mass-Transfer Resistance in Diffusive Sampling

Am. Ind. Hyg. Assoc. J. 46, 648-652 (1985)

In this paper, the authors expanded on the hypothesis of Tompkins and Goldsmith that depletion around the opening of a sampler occurs when external mass transfer resistance is significant compared with internal mass transfer resistance, and they demonstrated experimentally a simple method to 
correct for errors in diffusive sampling due to external mass transfer resistance. A diffusive sampler for water vapor was used to demonstrate the method of correction for external mass transfer resistance, the water vapor sampler used molecular sieve as the sorbent. Extrapolated concentrations of water vapor were compared with concentrations measured with a dew-point hygrometer. It was demonstrated that the effect of external mass transfer resistance in reducing the collection efficiency of diffusive samplers was not dependent on the analyte being sampled or the sorbent; the effect was observed for $\mathrm{SO}_{2}, \mathrm{NO}_{2}$, and water vapor uptake, wi th three different sorbents for water vapor (molecular sieve, concentrated $\mathrm{H}_{2} \mathrm{SO}_{4}$, and silica gel).

[50] Popendorf, W.

Vapor Pressure and Solvent Vapor Hazards

Am. Ind. Hyg. Assoc. J. 45, 719-726 (1984)

This paper discussed applications of vapor pressure to industrial hygiene and outlines the importance of vapor pressure as it affects airborne concentration and vapor hazard. The terms Vapor Hazard Ratio and its common logarithm, the Vapor Hazard Index (VHI), were introduced as the ratio of the physical concentration at the source (vapor pressure equivalent) to the acceptable concentration in the breathing zone. The VHI was claimed to provide a practical tool to predict the relative hazard of vapor concentrations of different solvents used in similar settings, to quantitatively evaluate or design ventilation systems, to improve a hazard rating or hazard communication system, or to influence environmental sampling strategies.

[51] Russwurm, G. M., Stikeleather, J. A., Killough, P. M., and Windsor, J. G., Jr.

Design of a Sampling Cartridge for the Collection of Organic Vapors Atmospheric Environment 15, 929-931 (1981)

In order to prevent inadvertent contamination of cleaned Tenax by improper handling, a new sampling cartridge was designed. The design, manufacturing procedure, and preliminary test results are given in this paper. The cartridge incorporates the standard glass sampling tube that seals the sorbent tube from external contamination. The Tenax-filled tube and sampling cartridge were assembled in a clean laboratory area, the sealing was checked by pressurizing the cartridge with prepurified nitrogen and monitoring the pressure. The cartridge was then brought to a positive pressure of 1 atmosphere and stored; as needed, the sampling cartridges were taken to the field in a pressurized condition.

[52] Samimi, B., and Falbo, L.

Comparison of Standard Charcoal Tubes with Abcor (NMS) Gasbadges within Controlled Atmosphere

Am. Ind. Hyg. Assoc. J. 46, 49-52 (1985)

In the effort reported in this paper, charcoal tubes were compared with Abcor (NMS) Gasbadges under controlled conditions within an inhalation chamber equipped with a dynamic air flow system. A calibrated infrared gas analyzer was used to monitor the concentration of organic solvent continuously throughout the experiments. The organic compounds used in the experiments were styrene, ethyl acrylate, and N-butyl acrylate. Samples were collected on 133 badges and 102 charcoal tubes under two different air velocities of $0.22 \mathrm{~m} / \mathrm{sec}$ and $0.44 \mathrm{~m} / \mathrm{sec}$. The results of the study suggest 
that prevalling air currents at the workplace should be regarded as a contributing factor to the rate of sample collection on passive dosimeters.

\section{[53] Senum, G. I.}

Theoretical Collection Efficiencies of Adsorbent Samplers

Environ. Sci. Technol. 15, 1073-1075 (1981)

This paper is a theoretical discussion of collection efficiencies of adsorbent samplers and, in particular, of breakthrough volume. Chromatographic response theory is applied to adsorption samplers and a breakthrough volume is defined and explicitly expressed in terms of a required collection efficiency, the retention volume for the adsorbate/absorbent combination, and the number of theoretical plates of the adsorbent. The breakthrough volumes derived in this paper are claimed to be exact for all $\mathrm{N}$ (number of theoretical plates of the adsorbent) since no approximations are involved.

[54] Spee, T.

Evaluation of an ISO Draft Proposal for Sampling and Analysis of Chlorinated Hydrocarbon Solvent Vapors in Workplace Atmospheres

Am. Ind. Hyg. Assoc. J. 47, 27-36 (1986)

This paper reports on the evaluation of an ISO draft proposal for sampling and analysis of chlorinated hydrocarbon solvent vapors in workplace atmospheres, by means of a round-robin test. The repeatability and reproducibility for the determination of tetrachloromethane, trichloromethane, trichloroethane, 1,1,1-trichloroethene, and tetrachlorethene were ascertained at three concentration levels; also, parameters such as breakthrough and loss on storage were determined. Samples were taken by 11 participants from 6 countries. The method described by the draft proposal is a pumped charcoal tube-solvent desorption gas chromatographic method. The collected organic vapors were desorbed by a suitable solvent and analyzed by means of a gas chromatograph with a flame ionization detector (FID). The author concluded that improvements in the method are necessary for the determination of tetrachloromethane and trichloromethane, that the method is sufficient for the other three compounds, and that a possible improvement of the method would be the prescription of an electron capture detector instead of an FID for compounds with a low FID sensitivity and low MAC values.

[55] Stockton, S. D., and Underhill, D. W. Field Evaluation of Passive Organic Vapor Samplers Am. Ind. Hyg. Assoc. J. 46, 526-531 (1985)

This paper reports on the evaluation of the performance of passive diffusion organic samplers manufactured by 5 companies and charcoal tubes manufactured by one company, in an industrial atmosphere known to contain vapor phase concentrations of benzene, toluene, and xylene. Six samplers of each type (36 in all) were exposed to essentially the same atmosphere. The collected organic vapor was desorbed by carbon disulfide and analyzed on a gas chromatograph with a flame ionization detector. The analytical results were treated with two-way analysis of variance, and the least significant difference test was applied to the mean values to further refine the data. The author concluded that each type of sampler could be used for industrial hygiene evaluations with confidence. 
[56] Underhill, D. W. Efficiency of Passive Sampling by Adsorbents Am. Ind. Hyg. Assoc. J. 45, 306-310 (1984)

It was the purpose of this paper to show how interactions between the sampled contaminant and the adsorbent (usually charcoal) affect the sampling efficiency and thereby prevent reversibility of diffusion in passive sampling. The effects of the interactions are reflected in the adsorption isotherm. Calculations of sampling efficiency were made in terms of dimensionless variables for adsorption controlled by the Langmuir, Freundlich, and Dubinin-Radushkevich $(D-R)$ isotherms, three common nonlinear isotherms. of particular interest were the results calculated from the $D-R$ isotherm, since it had been shown that this isotherm could accurately describe the adsorption of hydrocarbons and many related compounds on activated charcoal. The author concludes that 1) the effectiveness of a passive dosimeter depends strongly on the adsorption isotherm, 2) the $D-R$ isotherm is consistent with high sampling efficiency, and 3) the isotherms giving high sampling efficiency are also consistent with the retention of adsorbate for extended periods of time.

[57] Vasta, J. F., and Kvartek, E. J. Development of a Sampling and Analytical Method for the Insecticide Propoxur Am. Ind. Hyg. Assoc. J. 46, 230-232 (1985)

In this paper, a method for the collection and analysis of airborne propoxur (2-(1-Methylethoxy) phenol methylcarbamate) is described. Sorbent tubes for sampling consisted of glass tubes packed with $10 \%$ Carbowax 400 supported on $80 / 100$ mesh Supelcoport. The propoxur was desorbed by methanol and the extract was analyzed by high pressure liquid chromatography. The method was developed to collect low levels, about $0.1 \mathrm{ppb}$, of propoxur in air; the limit of detection of the analytical method was one $\mu \mathrm{g}$ per sample. Recoveries of greater than $87 \%$ were obtained from control samples evaluated at 0.5 and $1.0 \mathrm{mg}$.

[58] Wallace, L. A., Pellizzari, E. D., Hartwell, T. D., Sparacino, C. M., Sheldon, L. S., and Zelon, H.

Personal Exposures, Indoor-Outdoor Relationships, and Breath Levels of Toxic Air Pollutants Measured for 355 Persons in New Jersey Atmos. Environ. 19, 1651-1661 (1985)

The measurement methods and results for a second phase of E.P.A.'S Total Exposure Assessment Methodology Study are reported in this paper. Twenty toxic, carcinogenic, or mutagenic organic compounds were measured in the air and drinking water of 355 participants. Each participant carried a personal sampler during normal daily activities for two consecutive 12-hour periods (one participant residing in each of 100 areas had an identical sampler operating in the back yard for the same two 12-hour periods). All participants also collected two drinking water samples. Personal and outdoor air samples were collected for 12-hour periods on cartridges containing about 28 of $40 / 60$ mesh purified Tenax. The cartridges were analyzed by thermal desorption and cryofocussing of the organic vapors followed by capillary gas chromatography/mass spectrometry/computer analysis. About 3000 samples were collected, of which 1000 were quality control samples. 
[59] Wallace, L. A., Pellizzari, E. D., Hartwell, T., Rosenzweig, M., Erickson, M. D., Sparacino, C. M., and Zelon, H.

Personal Exposure to Volatile Organic Compounds; I. Direct

Measurements in Breathing Zone Air, Drinking Water, Food, and Exhaled Breath

Environ. Res. 35, 293-319 (1984)

This paper reports on a pilot study to test methods of estimating personal exposures to 20 target toxic substances and corresponding body burdens. One of the objectives of the volatile organics portion of the study was to test a personal monitor employing Tenax-GC adsorbent to collect selected organic compounds from breathing-zone air for 5-10 hours. The target compounds were selected on the basis of their extensive use and likely toxicity. All air exposures were measured using personal air quality monitors. All volatile organics except vinyl chloride were collected using glass tubes containing $1.5 \mathrm{~g}$ of Tenax-GC adsorbent. Samples were analyzed using thermal desorption and purging by helium into a liquid-nitrogen-cooled nickel capillary cryogenic trap, followed by high resolution glass column gas chromatography/mass spectrometry techniques. Vinyl chloride was collected using a dimethylsilicone rubber permeable membrane badge, the activated charcoal element was desorbed by carbon disulfide and the eluent analyzed using a gas chromatograph with electron capture detection. About 230 personal air samples, 170 drinking water samples, 66 breath samples, and 4 food samples were analyzed for the target chemicals.

[60] Walling, J. F., Bumgarner, J. E., Driscoll, D. J., Morris, C. M., Riley, A. E., and Wright, L. H. Apparent Reaction Products Desorbed From Tenax Used to Sample Ambient Air

Atmos. Environ. 20, 51-57 (1986)

This paper reports on the collection of ambient air samples using distributed air volume sets (see [61]) of tandem Tenax-GC beds. The distributed air volume sampling approach requires simultaneous collection of several samples, each at a very different flow rate. Many interfering processes scale nonlinearly with volume sampled; if they are important, apparent atmospheric concentrations become dependent on the volume sampled. This sampling approach does not permit identification or enumeration of interferences; however, the inclusion of tandem (two in series) beds and/or presampling spikes of deuterated species can assist in identifying adsorbate loss through inadequate retention. Tenax-GC of differing and uncontrolled histories was solvent-cleaned, desorbed, and packed in cartridges containing 1.2-g beds. Fifty-seven organic compounds, principally aromatic and halogenated hydrocarbons, were used. After sampling, the Tenax-GC was thermally desorbed and the eluent cryofocussed on a glass capillary in a gas chromatograph/mass spectrometer. Detection limits were between 1 and 3 ng. Inconsistent sets of apparent concentrations not due to contamination, operating errors, or blanks were often observed. Unidentified chemical reactions during sampling and/or thermal desorption were implicated. The authors concluded that, for aromatic and halogenated hydrocarbons, an empirical evaluation of data from each sampling situation using distributed air volume sets seemed necessary.

[61] Walling, J. F.

The Utility of Distributed Air Volume Sets When Sampling Ambient 
Air Using Solid Adsorbents

Atmos. Environ. 18, 855-859 (1984)

The distributed air volume sampling approach (see [60]) is illustrated in this paper by the use of Tenax-GC as the adsorbent. More than 100 peaks are typically observed in chromatograms of materials adsorbed from air and thermally desorbed from Tenax-GC. Quantitative interpretation of the data was complicated by the possible existence of at least three factors: 1) exceeding the capacity of the adsorbent; 2) inadequate blank corrections; 3) reactions usually called "artifact formation". Any substance removed from an adsorbent could be an atmospheric constituent or the result of reactions occurring during sampling or desorption. The underlying idea of the distributed air volume sampling approach is that at any fixed sampling rate the amount of a substance adsorbed will be a linear function of the volume sampled. Lack of dependence on volume is presumptive evidence that the results describe the atmosphere sampled, any artifact reaction which does not scale linearly with volume sampled should be revealed by the approach. Cleaned virgin Tenax-GC was packed into stainless steel sampling tubes. Analysis was by thermal desorption into a capillary gas chromatograph with mass spectrometric detection; analysis was confined to a set of 34 specific substances, principally aromatic and halogenated hydrocarbons. Sampling times ranged from 3 to 4 hours. Two different sampling-volume ranges were used, the initial arbitrary judgment was that the ratio of the largest to smallest volume sampled in each set should be about 5. The author concluded that because a distributed air volume set can reveal several kinds of behavior not correctly dependent on air volume, it is more useful for discovering difficulty in data than the conventional tandem bed approach and is just as practical to implement.

[62] Walling, J. F., Berkley, R. E., Swanson, D. H., and Toth, F. J. Sampling Air for Gaseous Organic Chemicals Using Solid Adsorbents. Application to Tenax

U.S. Environmental Protection Agency, Research and Development, Project Summary, EP-600/S4-82-059, December, 1982

This paper describes a simple input-output model for a two-phase flow system with fixed bed and its application to Tenax adsorption of atmospheric contaminants. The objectives of the work were: 1) to obtain a simple alternative model (applicable to field sampling with solid adsorbents) to standard chromatographic theory; 2) to test the accuracy of the function obtained in describing a few simplified controlled laboratory experiments; 3) to design a simple practical scheme for sampling and data interpretation which also could provide evidence of consistency in the results. The utility of the model was tested by simulated sampling using a permeation tube system to supply known concentrations of cleaned pollutant-doped air at various flow rates. Flame ionization detection of the output of the Tenax cartridge was utilized. Agreement of computed retention volumes with published values was generally within \pm 25 percent. The authors concluded that the model is capable of giving a reasonable and compact description of the sampling behavior of the Tenax cartridges over a range of variables likely to be met in the field. A suggested simplified approach for routine sampling is presented.

[63] Werner, M. D.

The Effects of Relative Humidity on the Vapor Phase Adsorption of 
Trichlorethylene by Activated Carbon

Am. Ind. Hyg. Assoc. J. 46, 585-590 (1985)

The purposes of this paper were: 1) to present results which illustrated the degree to which several levels of relative humidity reduced the adsorption capacity of activated carbon for a single volatile organic compound, trichloroethylene (TCE), at low influent concentrations; 2) to examine the interaction between TCE concentration and humidity during adsorption on carbon; 3) to suggest a potential approach that may be taken for predicting the degree of impact of relative humidity on the adsorption process. Experimental trials were performed at 4 concentrations of TCE (approximately $300,600,1000$, and $1300 \mathrm{mg} / \mathrm{m}^{3}$ ), each at 5 levels of relative humidity ( 5 , $25,50,65$, and $85 \%$ ). Temperature levels were maintained at $23+2{ }^{\circ} \mathrm{C}$. Determination of adsorption capacity was based on time to $50 \% \mathrm{TC} \overline{\mathrm{E}}$ breakthrough and the assumption of a symmetrical breakthrough curve. The author concluded that relative humidity at 5 different levels affected the adsorption capacity of activated carbon (for TCE); that, in general, each increase of humidity level further decreased the carbon's adsorptive capacity at all 4 concentrations of TCE tested; that the effect of relative humidity was greater at low TCE concentrations than at high TCE concentrations; that the Dubinin-Polanyi adsorption isotherm equation fit data at each humidity level equally well; and that the basis of the equation might be useful for predicting the effect of humidity on gaseous phase carbon adsorption.

[64] Willey, M. A., McCammon, C. S., and Doemeny, L. J. A Solid Sorbent Personal Sampling Method for the Simultaneous Collection of Nitrogen Dioxide and Nitric Oxide in Air Am. Ind. Hyg. Assoc. J. 38, 358-363 (1977)

A solid sorbent sampling tube for nitrogen dioxide $\left(\mathrm{NO}_{2}\right)$ and nitric oxide (NO) and a sampling method for the collection of air samples containing both $\mathrm{NO}_{2}$ and $\mathrm{NO}$ in the range 0.5 to $5 \mathrm{ppm} \mathrm{NO}$ and 9 to $50 \mathrm{ppm}$ NO, are described in $^{2}$ this paper. The sorbent sampling tube consisted of a pyrex glass tube containing two 400-mg sections of triethanolamine(TEA)-impregnated molecular sieve and one 800-mg section of oxidizer. A single solid sorbent tube could be used to sample in an occupational environment and collect $\mathrm{NO}_{2}$ and $\mathrm{NO}$. The $\mathrm{NO}_{2}$ was collected on the front section of TEA-impregnated molecular sieve, ${ }^{2}$ the $\mathrm{NO}$ was converted to $\mathrm{NO}_{2}$ by the oxidizer and then passed into another TEA-impregnated molecular ${ }^{2}$ sieve section where it was collected as $\mathrm{NO}_{2}$. The TEA sections were desorbed separately and analyzed by a spectrophotometer. At all concentrations tested, the collection efficiency for $\mathrm{NO}_{2}$ averaged approximately $96 \%$. The collection efficiencies for NO were: ${ }^{2}$ at $9 \mathrm{ppm}, 97 \%$; at $11 \mathrm{ppm}, 106 \%$; at $24 \mathrm{ppm}, 84 \%$; at $50 \mathrm{ppm}, 67 \%$. 


\section{B. STANDARD OPERATING PROCEDURES}

[P1] Berkley, R. E., Bumgarner, J. E., Driscoll, D. J., Morris, C. M., and Wright, L. H.

Standard Operating Procedure for the GC/MS Determination of Volatile Organic Compounds Collected on Tenax Environmental Monitoring Systems Laboratory

U. S. Environmental Protection Agency, Research Triangle Institute, N. C., Stanford Operating Procedure EMSL/RTP-SOP-EMD-02L, Revision 0, June 27,1984

This detailed standard operating procedure consists of thermal desorption of trace organic containants in air collected on tenax-GC porous polymer, separation of the collected compounds into fractions by high resolution capillary column gas chromatography, and analysis by low resolution electron impact mass spectrometry. A computer-assisted data reduction procedure, used to identify and "quantitative" selected compounds, was written specifically for the Finnegan 4023 gas chromatograph/mass spectrometry/ computer system; it may not be directly applicable to other instruments.

[P2] Berkley, R. E., Swanson, D. H., and Bumgarner, J. E. Standard Operating Procedure for the Preparation and Use of

Standard Organic Gas Mixtures in a Static Dilution Bottle Environmental Monitoring Systems Laboratory, U. S. Environmental Protection Agency, Research Triangle Park, N.C. Standard Operating Procedure EMSL/RTP-SOP-EMD-001, Revision 1, July, 1982

In this procedure, standard organic gas mixtures are prepared by injection of a quantity of liquid organic compound through a septum cap into a heliumfilled flask. A large number of different compounds may be injected, flasks with as many as 34 compounds had been used successfully. The flask is agitated and heated to achieve complete vaporization, after which aliquots of the vapor are delivered to sorbent cartridges or analytical instruments.

[P3] Berkley, R. E.

Standard Operating Procedure for the Preparation of Tenax Cartridges

Containing Known Quantities of Organics Using Flask Vaporization

Environmental Monitoring Systems Laboratory,

U. S. Environmental Protection Agency, Research Triangle Park, N.C.

Standard Operating Procedures EMSL/RTP-SOP-EMD-012,

Revision 0, November, 1981

In this procedure, a dilute solution of one or more organic compounds in methanol is heated in a heated zone $\left(310+10{ }^{\circ} \mathrm{C}\right)$ in a helium stream. The rapidly vaporized methanol and solute compounds are swept into a sorbent cartridge. Methanol has little affinity for Tenax-GC and is rapidly eluted from the cartridge. The solute compounds may be subsequently desorbed from the cartridge and delivered to an analytical instrument. The method may be used to spike quantitative standards on sorbent cartridges.

[P4] Bumgarner, J. E.

Standard Operating Procedure for the Preparation of Clean Tenax

Cartridges

Environmental Monitoring Systems Laboratory, 
U. S. Environmental Protection Agency, Research Triangle Park, N.C. Standard Operating Procedure EMSL/RTP-SOP-EMD-013,

Revision 0, November, 1981

This procedure covers the preparation of a batch of twenty Tenax-filled cartridges for sampling ambient air. The Tenax is cleaned in a Soxhlet apparatus using methanol and pentane as solvents. The Tenax is then dried by successively heating in air and in a vacuum oven, sieved into a breaker, and added through a powder funnel into a glass cartridge. The cartride is tapped gently to settle approximately 1.5 grams of Tenax. The packed cartridges are then conditioned (twenty at a time) at $270{ }^{\circ} \mathrm{C}$ under a helium purge.

[P5] Walling, J. F. and Bond, A. E.

Standard Operating Procedures for Sampling Gaseous Organic Air

Pollutants for Quantitative Analysis Using Solid Absorbents

Environmental Monitoring Systems Laboratory,

U. S. Environmental Protection Agency, Research Triangle Park, N.C.

Standard Operating Procedure EMSL/RTP-SOP-EMD-018, Revision 1, January, 1984.

This procedure provides instructions which permit defensible interpretations of analytical data for ambient air sampling for organic molecules. The sampling consists of drawing air through a cylindrical cartridge packed with a solid adsorbent. The preferentially adsorbed organic species are subsequently thermally desorbed into a gas chromatograph with mass spectrometric detection.

[P6] Blau, P. A.

Standard Operating Procedure for the Storage of Samples at the Field Sampling Site

Research Triangle Institute (Research Triangle Park, N.C.)

Standard Operating Procedure RTI/ACS-SOP-431-001 (Air), SOP-432-001

(Water), SOP-437-001 (Breath), Revision 1, April, 1984

This standard operating procedure gives the details of the routine for storing and preserving samples at the field sampling site, including methods for handling both Tenax (breath, air, and fixed site) and water samples. The procedure is applicable to any sampling trip/field site. Tenax samples require isolation and controlled atmosphere storage, water samples require refrigeration.

[P7] Brady, K. A.

Standard Operating Procedure for the Quantitation of Volatile Organic Compounds in Air and Breath Tenax Samples

Research Triangle Institute (Research Triangle Park, N.C.)

Standard Operating Procedure RTI/ACS-SOP-711-001 (Air), SOP-717-001

(Breath), Revision 0, January, 1984

This standard operating procedure describes the method used to "quantitate" the target compounds in air and breath Tenax samples that had been analyzed by gas chromotograph/mass spectrometer (GC/MS). Two BASIC computer programs were written to facilitate the quantitation. After each Tenax sample cartridge is analyzed, a data report listing the ion intensities or mass for each target compound is prepared; similar reports are prepared for the 
blanks and controls from each Tenax batch. The relative molar response of the instrument for each target compound is determined from analysis of cartridges loaded with known amounts of the targets, and the limits of detection for each instrument for the target compounds are determined. The concentrations of the targets present in the samples are determined using all this information.

[P8] Castillo, N. P.

Standard Operating Procedure for Preparing Response Factor Tenax

Cartridges Using a Permeation System

Research Triangle Institute (Research Triangle Park, N.C.)

Standard Operating Procedure RTI/ACS-SOP-630-005, Revision 0, May, 1984

This standard operating procedure describes the methodology for loading Tenax cartridges using a dynamic dilution (permeation) system. The permeation system consists of three parts: 1) a temperature-controlled chamber containing permeaton tubes; 2) a mixing chamber; 3) two cartridge holders enclosed in an insulated jacket. The loaded cartridges are used to determine the response factor of the gas chromotograph/mass spectrometer/ computer system. The procedure consists of the following steps: 1) selection of the permeation tubes; 2) determination of the loading conditions (flow rates and duration); 3) equilibration of the system; 4) checking of the background of the Tenax cartridges; 5) loading of the cartridges; 6) calculation of the amounts of compounds loaded; 7) assuring the integrity of the loading procedure; 8) adding the external standards.

[P9] Castillo, N. P.

Standard Operating Procedure for Preparing Response Factor and

Column Performance Evaluation Tenax Cartrides Using a Flash

Evaporation System

Research Triangle Institute (Research Triangie Park, N.C.)

Standard Operating Procedure RTI/ACS-SOP-630-006, Revision 0, May, 1984.

This standard operating procedure is essentially the same as [P14]; in the present case, the cartridges are to be used to determine response factor rather than relative molar response.

[P10] Castillo, N. P.

Standard Operating Procedure for Preparing Quality Control Samples

on Tenax Cartridges

Research Triangle Institute (Research Triangle Park, N.C.)

Standard Operating Procedure RTI/ACS-SOP-860-001, Revision 1, May, 1984

This standard operating procedure describes: 1) the steps to be followed to select and label quality control samples; 2) the loading of Tenax control cartridges with volatile organic compounds using a flask evaporation system; 3 ) the methodology for loading volatile organic compounds onto Tenax control cartridges from a permeation system. The two types of control samples are: 1) spiked cartridges ("controls") used to determine recoveries of target compounds after sampling; 2) unspiked cartridges ("blanks") used to determine the background of the Tenax cartridges and contamination associated with sample transport and storage. 
[P11] Castillo, N. P.

Standard Operating Procedures for Preparing Relative Molar Response

Tenax Cartridges Using a Permeation System

Research Triangle Institute (Research Triangle Park, N.C.)

Standard Operating Procedure RTI/ACS-SOP-630-001, Revision 0,

January, 1984.

This standard operating procedure is essentially the same at [P8]; in the present case, the cartridges are to be used to determine the relative molar response of the gas chromotograph/mass spectometer/computer system.

[P12] Castillo, N. P.

Standard Operating Procedure for Loading Deuterated Standards on

Tenax Cartridges Using a Permeation System

Research Triangle Institute (Research Triangle Park, N.C.)

Standard Operating Procedure RTI/ACS-SOP-630-004, Revision 0,

December, 1983.

This standard operating procedure describes the methodology for loading Tenax cartridges with deuterated standards using a permeation system. The loaded cartridges are subsequently used for sampling which allows for an assessment of premature breakthrough. The system may be used to load any volatile compound that will permeate at a constant rate under controlled conditions, and may be used to inject a calibration standard onto a sorbent using a syringe.

[P13] Castillo, N. P.

Standard of Operating Procedure for Loading External Standards on

Tenax Cartridges Via Injection Using a Permeation System

Research Triangle Institute (Research Triangle Park, N.C.)

Standard Operating Procedure RTI/ACS-SOP-630-003, Revision 0, December, 1983

This standard operating procedure describes the methodology for loading the external standards, perfluorobenzene (PFB) and perfluorotoluene (PFT) onto Tenax cartridges, by syringe injection from a permeation system. PFB is used an an external standard to determine relative retention times and relative response factors of the compounds to be "quantitated", PFT is used for determining instrument stability as related to mass resolution and relative ion abundance under gas chromatographic conditions.

[P14] Castillo, N. P.

Standard Operating Procedure for Preparing Relative Molar Response and Column Performance Evaluation Tenax Cartridges Using a Flash

Evaporation System

Research Triangle Institute (Research Triangle Park, N.C.)

Standard Operating Procedure RTI/ACS-SOP-630-002, Revision 0, December, 1983

The purposes of this standard operating procedure are: 1) to describe the methodology for preparing column performances evaluation (CPMX) solutions and relative molar response (RMR) solutions; 2) to describe the loading of Tenax-GC cartridges with volatile organic compounds and the CPMX components using a flash evaporation system. The method is applicable to organic compounds the breakthrough volumes (defined as the volume of gas required to 
elute 50\% of a compound introduced into one end of a cartridge) of wich are significantly greater than the volume of the diluting solvent. Also, the retention of the solvent by the Tenax-GC must be minimal. The main body of the flask evaporation system consists of a glass tube with an injection port, the tube is maintained at $250^{\circ} \mathrm{C}$ with heating tape. Any solution injected into the port is transported to a sorbent cartridge on line by a stream of helium gas. The CPMX solution is used to determine mass calibration of a gas chromatograph/mass spectrometer/computer (GC/MS/COMP) system. The RMR solution is used to determine the relative molar response of the GC/MS/COMP system.

[P15] Castillo, N. P. Standard Operating Procedure for the Storage of Air Breath Tenax Samples at Research Triangle Institute

Research Triangle Institute (Research Triangle Park, N.C.) Standard Operating Procedure RTI/ACS-SOP-481-001 (Air), SOP-487-001 (Breath), Revision 0, December, 1983

This standard operating procedure describes the proper manner of storing Tenax cartridges on which air and breath volatiles were collected, prior to analysis by a gas chromatrograph/mass spectrometer/computer system. A freezer reserved for Tenax cartridges was deemed to be essential since several studies had concluded that contamination of Tenax, both from external sources and from internal impurities, could be minimized by storing the cartridge at $-20{ }^{\circ} \mathrm{C}$.

[P16] Castillo, N. F. Standard Operating Procedure for Tenax Cleanup and Preparation of Tenax

Cartridges for Use in The Collection of Organic Compounds

Research Triangle Institute (Research Triangle Park, N.C.)

Standard Operating Procedure RTI/ACS-SOP-320-001, Revision 0, December, 1983

The two-fold purpose of this standard operating procedure was to: 1) describe the methodology for cleaning Tenax; 2) describe step by step the preparation and purification of the Tenax cartridges. The routine to be followed consists of selection, solvent extraction, drying and sieving of the Tenax; packing of the Tenax into glass cartridges; thermally desorbing the cartridges; ensuring the integrity of the cleaning and desorbing procedures; and packing and storage of the cartridges.

[P17] Porch, R. L.

Standard Operating Procedure for the Analysis of Volatile Organics Collected on Tenax Using the Finnigan 3300 GC/MS/DS

Research Triangle Institute (Research Triangle Park, N.C.)

Standard Operating Procedure RTI/ACS-SOP-533-002, Revision 0, April, 1984

This procedure, applicable to the qualitative and quantitative analysis of volatile organic compounds collected on Tenax GC, is related to optimal procedures for a particular instrument although the author claims that the basic method is adaptable to any gas chromatograph/mass spectrometer/data system (GC/MS/DS) with a suitable thermal desorption unit. Organic vapors collected on Tenax-GC is thermally desorbed, cryofocussed, and analyzed 
using the GC/MS/DS. The method is limited by the adsorption of water on the Tenax-GC since excess water will freeze the cryofocussing trap making quantitative analysis impossible. 
absorbing solution

accuracy

acetic acid

acetone

acetonitrile

acid aldehydes

acid halides

acid vapor

acrolein

acrylonitrile

activated carbon

adsorbent

adsorbent, porous polymer

activated charcoal

adsorbent beds, tandem

adsorbent tube

adsorbent tube, reagent-coated

adsorption

adsorption, volatile phase

adsorption, water

adsorption capacity

adsorption isotherm

adsorption of water

adsorption solvent

adsorption tube sampling system

air currents

air gap

airflow rate

air quality

alcohol

Amberlite

Ambersorb

amines

amyl alcohol

analysis of variance

analytical data

Anasorb

anhydrides

anhydrides, acetic

Arcolor

area sample

aromatic

aromatic diamine

aromatic polyimide resin

automated analysis

automated sequential syringe sampler
33

$10,17,25,36,39$

40,65

$7,24,41$

7

38

38

65

28

$8,9,11,41$

$28,29,59,63,67,68$

$1,12,13,16,22,28,30$, $31,43,53,56,59,60-62$, 65-67

$11, \mathrm{P} 1$

$22,24,41,56,59,65-67$

60,61

$13,31,37$

3

$1,12,24,29,53,56,62$

$63,65-68$, P5

63

P1?

63,65

56,63

P17

41

11,31

52

11

1

59

38

20,23

41

$3,23,38$

24

26,55

P5

20

38

38

13

26

48

18

18

12

32 


\begin{tabular}{|c|c|}
\hline $\begin{array}{l}\text { automatic two-channel air sampler } \\
\text { automation } \\
\text { automation, laboratory }\end{array}$ & $\begin{array}{l}48 \\
32,36,42 \\
36\end{array}$ \\
\hline $\begin{array}{l}\text { background } \\
\text { badge } \\
\text { badge, formaldehyde } \\
\text { badge, organic vapor } \\
\text { badge-type diffusion sampler } \\
\text { bag sample } \\
\text { benz[a]-anthracene } \\
\text { benzene } \\
\text { benzophenonetetracarboxylic acid } \\
\text { blank } \\
\text { body burden } \\
\text { breakthrough } \\
\text { breakthrough curve } \\
\text { breakthrough time } \\
\text { breakthrough volume } \\
\text { breath level } \\
\text { breath sample } \\
\text { breathing-zone air } \\
\text { bromine } \\
\text { butadiene, } 1 \text {, 3- } \\
\text { butene, } 2- \\
\text { butoxyethyl phosphonate, bis } \\
\text { butyl acrylate, N- }\end{array}$ & $\begin{array}{l}25,26, \mathrm{P} 8, \mathrm{P} 10 \\
20,33,34,59 \\
17 \\
25,33,34 \\
12,59 \\
6 \\
44 \\
11,12,25,39,55 \\
18 \\
15,37,59-61, \mathrm{P} 7, \mathrm{P} 10 \\
59 \\
24,54,63,66, \mathrm{P} 12 \\
63,65,66 \\
1,22,29,67 \\
8,13,22,53, \mathrm{P} 14 \\
58 \\
\mathrm{P}, \mathrm{P}, \mathrm{P} 15 \\
59,68 \\
15 \\
17 \\
15 \\
20 \\
52\end{array}$ \\
\hline $\begin{array}{l}\text { calibration } \\
\text { calibration curve } \\
\text { calibration factor } \\
\text { calibration standard } \\
\text { canister } \\
\text { capacity } \\
\text { capsule, sorbent } \\
\text { carbon, activated } \\
\text { carbon, graphitized } \\
\text { carbon dioxide } \\
\text { carbon disulfide } \\
\text { carbon sorbent } \\
\text { Carbopack } \\
\text { Carbosieve } \\
\text { Carbowax } \\
\text { cartridge } \\
\text { cartridge, respirator } \\
\text { centrifuge tube } \\
\text { charcoal } \\
\text { charcoal, activated } \\
\text { charcoal, coconut-based } \\
\text { charcoal, impregnated } \\
\text { charcoal cloth } \\
\text { charcoal tube }\end{array}$ & $\begin{array}{l}10,14-16,28,39 \\
10,28,43 \\
10 \\
28, \mathrm{P} 12 \\
1 \\
5,25,61,66 \\
42 \\
28,29,56,59,63,66-68 \\
47 \\
44 \\
24,41,55,59 \\
15,47 \\
15 \\
8,41 \\
15,28,57 \\
1,15,37,43-48,51,58, \\
60,62,66,67, \mathrm{P} 2-\mathrm{P} 17 \\
66,67 \\
30 \\
17,22,24,35,48,52,55, \\
56 \\
22,24,41 \\
24 \\
17,30 \\
4 \\
17,19,35,36,52,54,55\end{array}$ \\
\hline
\end{tabular}


charcoal tube/solvent desorption, pumped Chemical Defense Establishment

Chemical Research and Development Center chemical transformation chemisorption

chlorinated hydrocarbon solvent vapor chloroacetly chloride chloroethyl ethyl sulfide

chloride

chlorine

chloroform

chlorotrifluoroethylene

chromatograph column vibrator

chromatographic theory

chromatography

Chromosorb

cleaning of Tenax-GC

collection, simultaneous

collection efficiency

collection of samples

colorimeter

colorimetric analysis

column performance

computer-assisted data reduction

concentration, vapor

concentration gradient

concentration level

concentration profiles

conductimetric detector

contaminant

contaminant concentration

contamination

control

cresol

cryofocussing

cryogenic trap

cyclohexane- $\mathrm{d}_{10}$

cyclohexene

data interpretation

decomposition of chemical substances

decomposition products

degradation

derivatization

desiccant

desorption

desorption, whole-tube

desorption efficiency
54

4,20

20

45

1,3

54

38

20

40

15

27,29

19

22

53,62

$3,15,36,57$

$1,2,5,14,24,27,28,47$,

65

P4

64

$22,49,53,64$

$20,48,57,60,65,67, \mathrm{P} 16$ 5

33,34

P9, P14

P1

$13,14,17,50,60$

12

25, 26, 54, P7

39

30

$1,13,15,22,26,37,51$, $56,60,62,66,67, \mathrm{P} 1, \mathrm{P} 10$, P15

67

51

$26,57,58, \mathrm{P} 7, \mathrm{P} 10$

68

$37,58,60, \mathrm{P} 17$

48

45

15

62

15

46

3,46

$3,23,28,38$

5,6

$2,5,7,14,19,22,24,25$,

$27,28,36,37,41,42,44$,

$45,54,55,57,61,64,65$,

P1, P5, P16, P17

36

7,28 


\begin{tabular}{|c|c|}
\hline desorption solvent & 14,28 \\
\hline $\begin{array}{l}\text { detection, limit of } \\
\text { detector. nitrogen-selective }\end{array}$ & 57,60 \\
\hline $\begin{array}{l}\text { detector, nitrogen-selective } \\
\text { deuterated compounds }\end{array}$ & $\begin{array}{l}41 \\
45,60\end{array}$ \\
\hline deuterated standard & P2, P12 \\
\hline dew-point hygrometer & 49 \\
\hline diamine, aromatic & 18 \\
\hline diatomaceous earth & 65 \\
\hline dichloroacetic acid & 40 \\
\hline dichlorodiethyl ether, 2,2'- & 2 \\
\hline $\begin{array}{l}\text { diethylamine } \\
\text { diethylether }\end{array}$ & 23 \\
\hline $\begin{array}{l}\text { diethylether } \\
\text { diffuser element, multi-cavity }\end{array}$ & \\
\hline diffuser element, multi-cavity & 17 \\
\hline diffusion & $10,33,55,56$ \\
\hline diffusion, molecular & 6 \\
\hline diffusion monitor, passive & \\
\hline diffusion sampler, badge-type & 12,59 \\
\hline diffusional resistance & 4 \\
\hline diffusive sampler & $10,11,16,20,49$ \\
\hline diffusive sampling & 49 \\
\hline diffusive uptake & 16 \\
\hline diisopropyl methylphosphonate & 20 \\
\hline dilution & 43 \\
\hline dimethylamine & 23 \\
\hline dimethyldichlorosilane & 27 \\
\hline dinitrotoluene & 27 \\
\hline displacement & 24 \\
\hline distilled deionized water & 17,40 \\
\hline distilled water deorption & 65 \\
\hline distributed air volume sets & 60,61 \\
\hline dosimeter & $25,39,42,52$ \\
\hline dosimeter, passive & $25,39,42,50$ \\
\hline $\begin{array}{l}\text { dosimeter system, multisorbent passive } \\
\text { dosimetry }\end{array}$ & 42 \\
\hline $\begin{array}{l}\text { dosimetry } \\
\text { drving agent }\end{array}$ & 4 \\
\hline drying agent & 5 \\
\hline dual-bed collection tube & 8 \\
\hline Dubinin-Polanyi adsorption isotherm & 63 \\
\hline Dubinin-Radeshkevich adsorption isotherm & 56 \\
\hline Duncan's multiple range test & 26 \\
\hline dynamic atmosphere generation & 9,41 \\
\hline $\begin{array}{l}\text { dynamic dilution system } \\
\text { dynamic sample }\end{array}$ & $\begin{array}{l}\mathrm{P} 8, \mathrm{P} 9, \mathrm{P} 11 \\
4\end{array}$ \\
\hline $\begin{array}{l}\text { dynamic sample } \\
\text { dynamic vapor pressure system }\end{array}$ & $\begin{array}{l}4 \\
35,39\end{array}$ \\
\hline efficiency & 25,26 \\
\hline electrochemical fuel cell & 17 \\
\hline electron capture detector & $7,15,36,54,59,71$ \\
\hline electron impact mass spectrometry & P1 \\
\hline emission, source & 26 \\
\hline environment & $33,64,65$ \\
\hline environmental sampling & 50 \\
\hline ethanol & 24 \\
\hline ethene & 44 \\
\hline ethyl acrylate & \\
\hline
\end{tabular}


ethylamine 23

ethylene $\quad 15$

ethylene chloride 28

ethylene oxide $\quad 33,34$

ethylenediamine

evaluation, field

3

exhaled air

$6,10,11,15,55$

explosive

exposure

exposure, time-weighted

exposure, time-weighted average

exposure agent

exposure concentration

exposure limit, short-term

exposure period

exposure time

external air movement

59

7

$16,26,39,58,59$

16

$17,19,35$

6

10,35

17,25

16

10,12

external flow effects

10

external mass-transfer resistance

external standard

11

49

face velocity

field comparison

field evaluation

field sampling

field spiking

field testing

field validation

field verification

filter, glass fiber

filter, reactive

filter, Teflon

filtration

fixed bed

fixed site sample

flame ionization detector

flame photometer detector

flash vaporization

Florisil

flow system, two-phase

flowrate

flowrate, kinetic saturation

$36,38, P 8, P 9, P 11, P 13$

$12,15,25$

6

$6,11,15,55$

$35,46,47,62, \mathrm{P} 6$

9

$10,11,17,19$

8,9

$9,33,34$

15

40

46

$30,45,46$

62

P6

$2,15,19,22,24,28,29$, $35,36,39,41,54,55,62$

21

P3, P9, P10, P14

7,14

62

$13,22,24,39,44,60,62$,

$67, \mathrm{P} 8, \mathrm{P} 9, \mathrm{P} 11$

22

23

40

fluoride

fluorimeter

food

formaldehyde

formaldehyde badge

formal demeter

formate

formation of chemical substances

formic acid

5,17

59

$5,17,30,34$

17

17,34

30

15

65 
free fatty acid phase

freezer

gas adsorption kinetics

gas badge

Gas Chrom

gas chromatography

gas chromatography/mass spectrometry

gas chromatography/mass spectrometry/ computer system

gas liquid chromatography

gas-tight syringe

generation, vapor

glycolic acid

grab sampler

graphitized carbon

gravimetry

halogenation

hazardous vapor

hazards

heat transfer

hexane

high-performance liquid chromatography

high-performance thin layer chromatography

high-pressure liquid chromatography

humidity

hydraquinone

hydrazine

hydrazoic aid

hydrocarbon

hydrocarbon, aromatic

hydrocarbon, halogenated

hydrocarbon, trichlorinated

hydrochloric acid

hydrofuran

hydrophobicity

impinger

impinger method, xylene

impinger/polarographic system

impregnated charcoal

impregnated charcoal tube

in situ measurement

in situ reaction

indoor-outdoor relationships

industrial hygiene

inertness
$2,24,27$

P15

66,67

52

$7,21,29$

$2,7,8,11,13,15,18-20$,

$2224,25,27-29,35-37,39-$

$41,43,44,48,54,55,59$,

$61-63,68, \mathrm{P} 1, \mathrm{P} 5, \mathrm{P} 13$

$43,45,46,59,60,61, \mathrm{P} 1$,

$\mathrm{P} 5, \mathrm{P} 7-\mathrm{P} 9, \mathrm{P} 11$

$15,37,58, \mathrm{P} 1, \mathrm{P} 8-\mathrm{P} 11, \mathrm{P} 14$, P15, p17

15

43

7

40

31

47

11

45

$37,47,50$

50

1

$14,22,38$

$3,23,57$

38

57

$4,8,10-14,16,21,23,25$,

$29,34,35,38,40,41,63$

28

17

65

$48,56,60$

$44,48,60,61$

$15,48,60,61$

66

65

3

7

65

21

17

30

17

31

45

58

$9,26,35,36,50,55,66$, 67 
inf rared analyzer

inhibition

inorganic gas

inorganic gas, reactive

interactions

interference

internal mass transfer resistance

ion chromatography

ion-exchange chromatography

isocyanate

isocyanatoethyl methacrylate

isopropanol

iso-octane

kinetic adsorption

kinetic saturation capacity

laboratory automation

laboratory experiment

laboratory robot

laboratory test

laboratory validation

leaching

least significant difference test

limit of detection

loading of cartridge

loading of deuterated standard

loading of external standard

low-volatility compounds

mass spectrometry

mass spectrometry, low resolution electron

impact

mechanical shaker

methane

methanol

methyl acetate

methyl benzilate

methyl salicylate

methylamine

microcomputer-controlled syringe

miniature passive dosimeter

Minimonitor

minimum detectable quantity

moisture

molar response, relative

molecular diffusion

molecular sieve

monitor, passive diffusion

monitoring

monitoring, real-time

monitoring badge, organic vapor

monitoring badge, passive air
6,52

45

46,48

46

56

$5,10,17,21,38,48,60$

49

30,40

30

38

38

24

39

29

22

36

$10,11,15,18,19,62$

36

$17,42,48$

$19,33,34,35,41$

68

55

$41,57, \mathrm{P7}$

P8, P10

P12

P13

2

P1

P1

23,38

44

$14,15,24,57, \mathrm{P3}, \mathrm{P} 4$

66

20

2

23

31

25

20

3

29

P7, P11, P14

6

$6,16,49,64$

6

$9,11,17,25,31,34,36$, 38,41

6

20

33,34 
monochloroacetic acid

multicavity diffuser element

multicomponent volatile organic standard

43

multiple comparisons

multisorbent passive dosimeter

10

42

N-butyl acrylate

52

National Bureau of Standards

39

NBD chloride

nitric oxide

nitrogen

nitrogen dioxide

nitrogen-selective detector

nitrosation

nitrous oxide

non-polar organic vapors

23

64

13,15

49,64

41

45

6,16

24

organic analysis, vapor phase

18

organic chemical, gaseous

organic compounds

organic compounds, volatile

organic gases

organic pollutants

organic solvent concentration

organic vapor

organic vapor monitoring badge

oxidant

oxidation

oxidizer

ozone

ozonization

\section{packing}

passive air monitoring badge

passive diffusion monitor

passive dosimeter

passive dosimeter system, multisorbent

passive sampling

passive organic vapor sampler

passive sampler

pentachlorophenols

pentane

perfluorobenzene

perfluorotoluene

permeable membrane badge

permeation

permeation system

permeation tube

phenol

phosphine

62

$46,58,60, \mathrm{P} 1, \mathrm{P3}, \mathrm{P} 5, \mathrm{P} 16$

$17,37,59,62,63, P 7, P 10$, P14, P17

$46, \mathrm{P} 5$

$48, \mathrm{P} 5$

52

$2,12,13,20,24,25,37$,

$45-47,51,54,55,58$

20,25

17,46

3,45

64

46

45

$14,65, \mathrm{P} 4, \mathrm{P} 16$

33,34

6

$25,39,42,52$

42

4, 57

55

$4,31,55,56$

68

15, P4

P13

P13

59

10

$\mathrm{P} 8-\mathrm{P} 13$

62, P8, P9 P11

68

21

21

21 
phoroionization detector $\quad 39$

piperazine 38

polar organic vapors $\quad 24$

polarographic reduction 7

pollutant

$12,13,25,31,37,47,48$,

polycyclic aromatic hydrocarbon

$58,59,62, \mathrm{P5}$

polyimide resin, aromatic

44

18

polymer, porous

21

polymellitic dianhydride

18

polynuclear aromatic hydrocarbon 44

polymeric beads $\quad 37$

polymerization inhibitor $\quad 28$

polypropylene

Porapak

precision

preconditioning, thermal

prediction

pressure

pressure drop

propane

propoxur

propylene

protocol

pump, personal sampling

pump/charcoal tube sampling method

4

pump/impinger sampling method

pump method, conventional

$11,12,19,20,47$

$8,10,16,21,25,36,39$,

43

15

$63,66,67$

$10,21,34,51$

65

44

57

15

10

$19,21,24$

33

34

16

quality assurance

quality assurance standards

quality control

quantitative analysis

quantitative standards

quartz fiber, impregnated

48

43

48, P10

P5

P3

40

RDX vapors

reaction

reaction, chemical

reaction, halogenation

reaction, nitrosonation

reaction, ozonization

reaction products, apparent

reactive chemicals

reactive chemicals, airbome

reactive filter

reactive gases

reactive inorganic gases

reagent

recovery

recovery, sample

relative molar response

relative response factor

\section{7}

$5,15,60,61$

60,61

45

45

45

60,61

38

38

40

15

46

33,38

$8,9,14,30,38,57, \mathrm{P} 10$

$4,65,68$

P7, P11, P14

P13 


$\begin{array}{ll}\text { reliability } & 36 \\ \text { resolution } & 44 \\ \text { residence time } & 1 \\ \text { respirator } & 1 \\ \text { response factor } & \mathrm{P} 8, \mathrm{P} 9 \\ \text { retention } & 56,57,60,62, \mathrm{P} 14 \\ \text { retention time } & 28 \\ \text { retention time, relative } & \mathrm{P} 13 \\ \text { retention volume } & 13,18,53,62 \\ \text { reversibility } & 56 \\ \text { robotics } & 36 \\ & \\ \text { safe sampling volume } & 13 \\ \text { sample } & 23,25, \mathrm{P} 6, \mathrm{P} 10 \\ \text { sample recovery } & 4 \\ \text { sample tube } & 8 \\ \text { sample, air } & \mathrm{P} 6, \mathrm{P} 7, \mathrm{P} 15 \\ \text { sample, area } & 26 \\ \text { sample, breath } & \mathrm{P} 6, \mathrm{P} 7, \mathrm{P} 17 \\ \text { sample, fixed site } & \mathrm{P} 6 \\ \text { sample, gaseous atmospheric } & 49 \\ \text { sample, replicate } & 15 \\ \text { sample, transfer of } & 48 \\ \text { sample, transportation and storage } & 25 \\ \text { sample, water } & \mathrm{P} 6 \\ \text { sampler } & 16,20,32,35,47,49,53, \\ & 55,58 \\ \text { sampler performance } & 10,47,55 \\ \text { sampler, adsorbent } & 53 \\ \text { sampler, air, automatic, two-channel } & 48 \\ \text { sampler, grab } & 31 \\ \text { sampler, liquid, automatic } & 35 \\ \text { sampler, personal } & 31,58 \\ \text { sampler, syringe, automated sequential } & 32 \\ \text { sampler, tube-form } & 11,12 \\ \text { sampling } & 5,9,10,16,18-20,21,23, \\ & 24,26-28,30,31,33,35- \\ & 37,40-42,45-51,53-58,60- \\ \text { sampling and analysis } & 62,64,65,68, \mathrm{P} 4, \mathrm{P} 5, \mathrm{P} 12 \\ \text { sampling efficiency } & 54 \\ \text { sampling pump } & 56 \\ \text { sampling time } & 21 \\ \text { sampling system, adsorption tube } & 31 \\ \text { sampling tube } & 11,31 \\ \text { sampling, air } & 5,21,27,30,61,65 \\ \text { sampling, field } & 26,33,45,50,60, \mathrm{P} 5 \\ \text { sampling, personal } & 35,46,47,62, \mathrm{P} 6 \\ \text { sensitivity } & 58,64,68,16,19,21,24, \\ \text { sequential grab sampler } & 17,25,28,68 \\ \text { sequential monitoring } & 31 \\ \text { sequential syringe sampler } & 32 \\ \text { service life } & 66,67 \\ & \\ & \\ & \\ & \\ & \end{array}$


shaker, mechanical

short-term exposure limit (STEL)

silica gel

simulated sampling

simultaneous collection

sodium bicarbonate

sodium bisulfite

sodium carbonate

sodium hydroxide solution

sodium thiosulfate

solid adsorbent

solid sorbent

solid sorbent sampling tube

solvent

solvent desorption

solvent extraction

solvent vapor hazard

sorbent

sorbent background

sorbent bed

sorbent, carbon

source sampling

Soxhlet extraction

spectrophotometer

spike

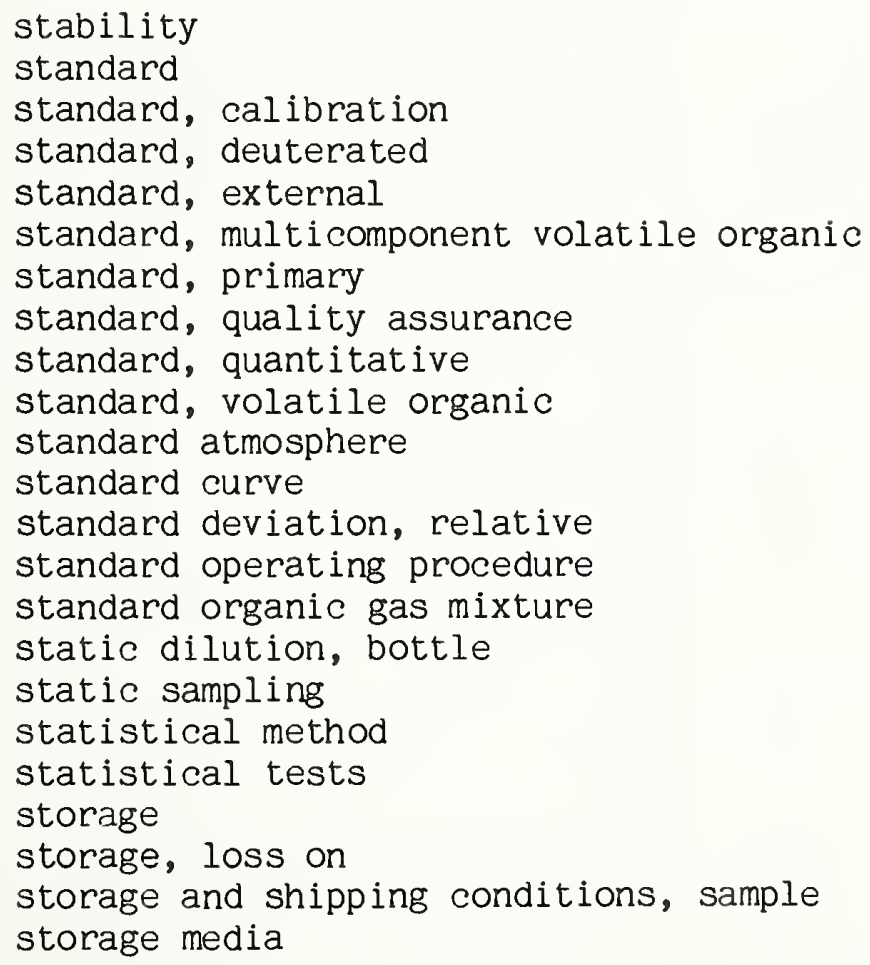

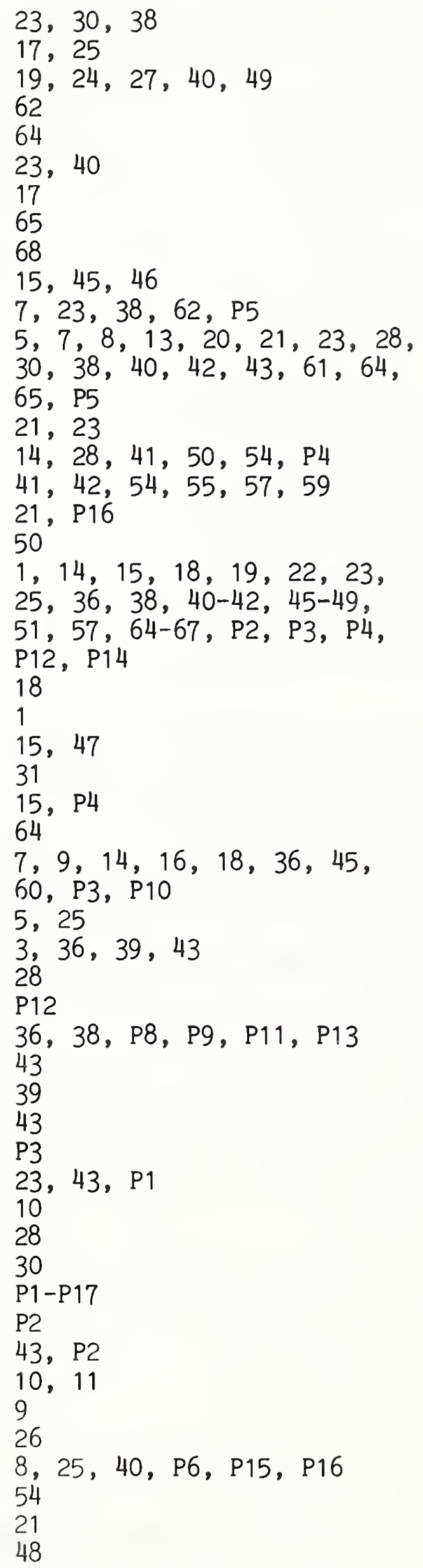




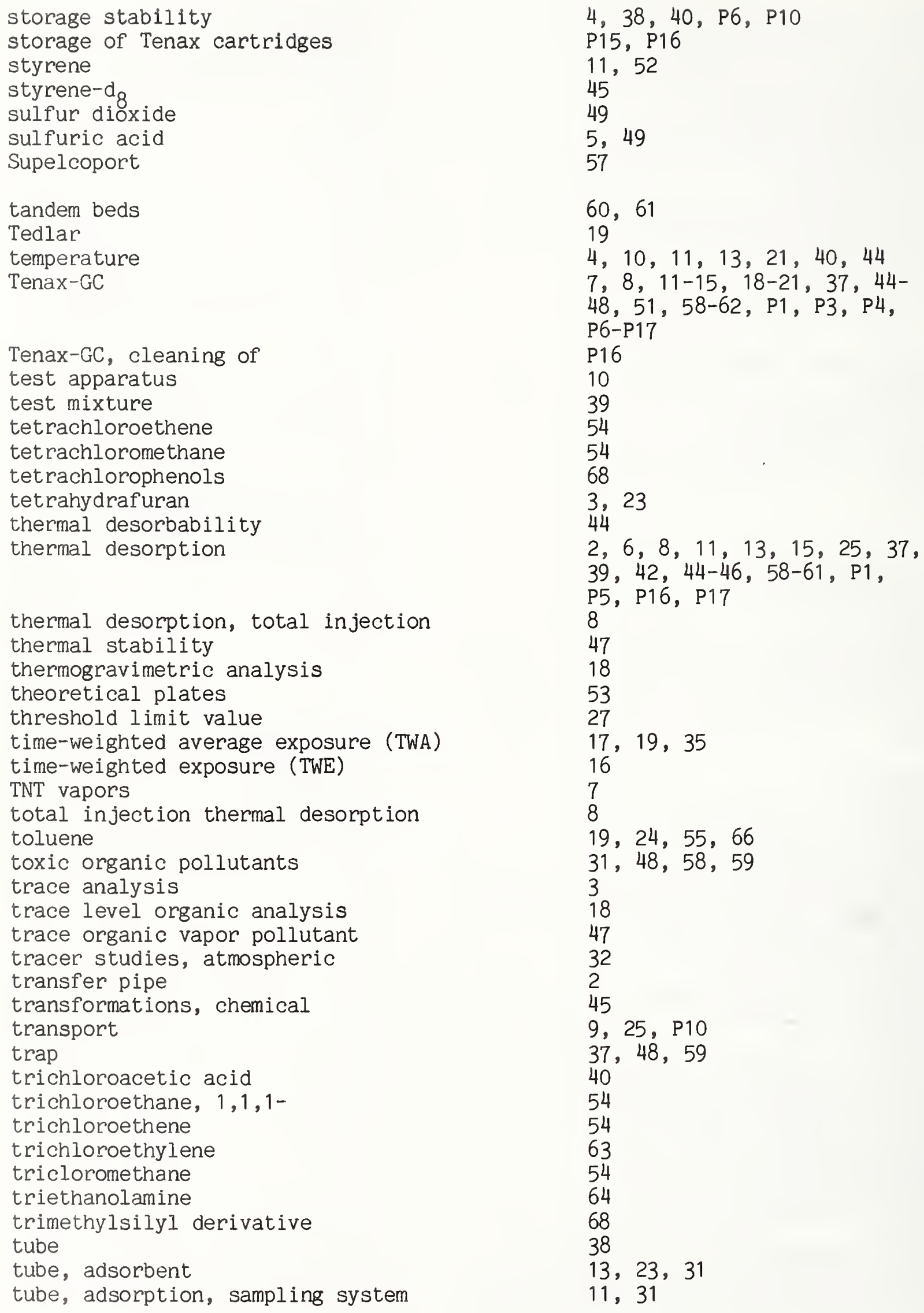


tube, charcoal

tube, charcoal, impregnated

tube, sorbent

tube-type diffusive sampler

turbulence

two-phase flow

ultra-sonic bath

ultraviolet absorptivity

ultra-violet/visible detector

uptake, diffusive

uptake rate

uptake rate, standard

U.S. Air Force

validation

validation, field

validation, laboratory

valve, gas sampling

verification, field

vapor exposure system, dynamic

vapor hazard ratio

vapor hazard index

vapor pressure

vibrator, chromatograph column

vinyl chloride

volatile compound

volatility

vortexing

water, distilled deionized

water, low retentive index for

water vapor

water vapor, affinity for

whole tube desorption

XAD-2

xylene
$35,36,52,54,55$

17

$14,22,40,57$

12

12

62

30

3

23

16

10

10

6

$8,34,40,41$

9

$33-35,41$

8

33,34

39

50

50

12,50

22

59,66

P12

2

14

40

47

$5,13,21,29,38,40,49$

13

36

$3,12,14,15$

$21,24,55$ 
Ackley, M.W.

Alder, J.F.

Anderson, $\mathrm{K}$.

Ansul, G.R.

Ayers, T.A.

Bailey, A.

Baldwin, C.L.

Barrett, W.J.

Basilio, A.N., Jr.

Benner, R.

Berkely, R.E.

Bisgaard, P.

Bishop, E.C.

Bishop, R.W.

Blau, P.A.

Bond, A.E.

Borders, R.A.

Bouyoucos, S.

Brady, K.A.

Brown, R.H.

Brownlow, C.S.

Bryant, M.L.

Bumgarner, J.

Bunch, J.E.

Campbe11, R.A.

Castillo, N.P.

Charlton, J.

Cook, R.E.

Cooper, S.

Coyne, L.B.

Cox, P.C.

Crouse, W.E.

Damrell, D.J.

Demain, B.

Demaray, D.E.

Dietz, E.A., Jr.

Dillon, H.K.

Dixon, S.W.

Doemeny, L.J.

Douglas, J.J.

Driscoll, D.J.

Easley, L.D.

Eller, P.R.

Elskamp, C.J.

Erickson, M.D.

Esposito, G.G.
1

2

3

$33,34,45$

7

4

17

21

33,34

32

$43,47,62, \mathrm{P1}, \mathrm{P2}, \mathrm{P3}$

5

6

7

P6

P5

$8,9,41$

17

P7

$10,11,12,13,16$

14

20

$43,60, P 1, P 2, P 4$

15,47

36

P8-P16

11

17

48

$17,36,41$

16

26

33

18,46

31,32

19

$20,21,40$

35

64

33

60, P1

22

21

23

59

65 
Falbo, L. $\quad 52$

Farris, T.S. 29

Fowler, W.F. 20

Geraci, C.L. Jr. $\quad 30$

Glaser, R.A. 40

Gluck, S.J. 8,9

Goller, G.W. 24

Gonzalez, J. 25, 39

Gutknecht, W.F. 48

Hallgren, C. 3

Hardison, D. 48

Hartwell, T.D. $\quad 58,59$

Harvey, R.P. 10

Heitbrink, W.A. 26

Hemingway, R.E. 35

Henry, T.T. 33, 35

Hildebrand, E.A. 2

Hodgson, A.T. 49

Hoffman, V.J. 19

Hollingdale-Smith, P.A. 4

Hossain, M.A. 6

Hubbard, S.A. 37

Hunt, R.J. 27

hurley, G.F. 28

Jonas, L.A. 29

Kastl, P.E. 36

Ketcham, N.H. 28

Killough, P.M. 51

Kim, W.S. $\quad 30$

Krasnec, J.P. 31, 32

Kring, E.V. 33, 34, 35, 39

Kristensen, T.J. 44

Kropscrott, B.E. 36

Krost, K.J. 37

Kupel, R.E. 30

Kvartek, E.J. 57

Lam, L. 18

Lamb, B. 32

Langhorst, M.L. 38

Lefebre, H. 42

Levin, J.-0. 3

Levine, S.P. 25, 39

Martin, J.J. 20

Mason, D.W. 40

McCamnon, C.S., Jr. 64

McDonald, O.F. 17

McGibney, P.D. 33, 34

McRae, J. 47

Melcher, R.G. 8, 9,41 


\begin{tabular}{|c|c|}
\hline $\begin{array}{l}\text { Molhave, L. } \\
\text { Moore, G. } \\
\text { Morello, J.A. } \\
\text { Morris, C.M. }\end{array}$ & $\begin{array}{l}5 \\
42 \\
35 \\
43,60, P 1\end{array}$ \\
\hline $\begin{array}{l}\text { Nann, J.R. } \\
\text { Nelson, J.H. } \\
\text { Neubauer, N.R. } \\
\text { NiIsson, C.-A. }\end{array}$ & $\begin{array}{l}17 \\
66,67 \\
27 \\
3\end{array}$ \\
\hline$O^{\prime}$ Dell, H.L. & 34 \\
\hline $\begin{array}{l}\text { Pankow, J.E. } \\
\text { Pellizzari, E.D. } \\
\text { Persoff, P. } \\
\text { Picone, R.F. } \\
\text { Popendorf, W. } \\
\text { Porch, R.L. } \\
\text { Purnell, C.J. }\end{array}$ & $\begin{array}{l}44 \\
15,18,37,45,46,47,48,58,59 \\
49 \\
27 \\
50 \\
\text { P17 } \\
10,13\end{array}$ \\
\hline Que Hee, S.S. & 14 \\
\hline $\begin{array}{l}\text { Reinhart, D.S. } \\
\text { Reitz, A.E. } \\
\text { Riley, A.E. } \\
\text { Rosenzweig, M. } \\
\text { Russwurm, G.M. }\end{array}$ & $\begin{array}{l}7,65 \\
5 \\
60 \\
59 \\
51\end{array}$ \\
\hline $\begin{array}{l}\text { Samimi, B. } \\
\text { Sansone, E.B. } \\
\text { Sarver, E.W. } \\
\text { Saunders, K.J. } \\
\text { Schindler, A. } \\
\text { Schultz, G.R. } \\
\text { Senum, G.I. } \\
\text { Sheldon. L.S. } \\
\text { Sowle, W.F. } \\
\text { Sparacino, C.M. } \\
\text { Spee, T. } \\
\text { Steinle, S. } \\
\text { Stephens, J.S. } \\
\text { Stikeleather, J.A. } \\
\text { Stockton, S.D. } \\
\text { Suggs, H.J. } \\
\text { Swanson, D.H. } \\
\text { Sykes, J.A.W. }\end{array}$ & $\begin{array}{l}52 \\
29 \\
20 \\
10, \quad 11 \\
18 \\
23 \\
53 \\
58 \\
8,36 \\
58,59 \\
54 \\
42 \\
34 \\
51 \\
55 \\
22 \\
62, \quad P 2 \\
2\end{array}$ \\
\hline Toth, F.J. & 62 \\
\hline Underhill, D.W. & 55,56 \\
\hline Vasta, J.F. & 35,57 \\
\hline $\begin{array}{l}\text { Walburn, S.G. } \\
\text { Walkin, K.T. }\end{array}$ & $\begin{array}{l}37 \\
12\end{array}$ \\
\hline
\end{tabular}




$\begin{array}{ll}\text { Wallace, L.A. } & 58,59 \\ \text { Walling, J.F. } & 60,61,52, \text { P5 } \\ \text { Werner, M.D. } & 63 \\ \text { Wilhardt, P. } & 5 \\ \text { Willey, M.A. } & 64 \\ \text { Williams, K.E. } & 65 \\ \text { Windsor, J.G., Jr. } & 51 \\ \text { Wright, L.H. } & 60, \text { P1 } \\ \text { Yoon, Y.H. } & 66,67 \\ \text { Yrjanheikki, E. } & 68 \\ \text { Zelon, H. } & 58,59\end{array}$


NBS-114A (REV. 2-80)

U.S. DEPT. OF COMM

BIBLIOGRAPHIC DATA

SHEET (See in structions)

1. PUBLICATION OR

REPORT NO.

NBSIR $87-3527$

2. Performlns Organ. Report No. 3. Publication Date

February 1987

4. TITLE AND SUBTITLE

Collection and Analysis of Organic Compounds in Air: An Annotated

Bibliography (1976-1986)

5. $\operatorname{AUTHOR}(S)$

Frank E. Jones

6. PERFORMING ORGANIZATION (If joint or other than NBS, see in structions)

7. Contract/Grant No.

NATIONAL BUREAU OF STANDARDS

DEPARTMENT OF COMMERCE

WASHINGTON, D.C. 20234

9. SPONSORING ORGAIHZATION NAME AND COMPLETE ADDRESS \{Street, City, Stote, ZHF\}

Commander

Chemical Research Development and Engineering Center

SMCCR-RSP-P/Dr. Amnon Birenzvige

Aberdeen Proving Ground, MD 21010-5423

10. SUPPLEMENTARY NOTES

Document describes a computer program; SF-185, FIPS Software Summary, is attached.

11. ABSTRACT (A 200-word or less foctual summary of most significant information. If document includes a significant bibliography or literature survey, mention it here)

This is a selected and annotated bibliography of sources of methodology for the collection and analysis of volatile and semi-volatile organic compounds present in air. The most prevalent methodology is the collection and preconcentration of organic compounds in a tube or cartridge containing an adsorbent, and subsequent thermal desorption of the collected compounds on the column of a gas chromatograph (GC), GC/mass spectrometer (MS), or GC/MS/computer system for analysis. The performance of adsorbents such as porous polymer adsorbents, and the optimization and standardization of methodology are of particular interest. The bibliography comprises 68 general citations and 17 standard operating procedures.

12. KEY WORDS (Six to twelve entries; alphabetical order: capitalize only proper names; and seporate key words by semicolons) Adsorption; adsorbent cartridges; bibliography; analysis; GC/MS/computer systems; porous polymer adsorbents; standardized methodology; thermal desorption; volatile and semi-volatile organic compounds

13. AVAILABILITY

[x] Unlimited

For Official Distribution. Do Not Release to NTIS

Order From Superintendent of Documents, U.S. Government Printing Office, Washington, D.C. 20402.

14. NO. OF

PRINTED PAGES

\section{7}

15. Price

X] Order From National Technical Information Service (NTIS), Springfield, VA. 22I6I

$\$ 13.95$ 
